Review

\title{
Protease Inhibitors from Marine Venomous Animals and Their Counterparts in Terrestrial Venomous Animals
}

\author{
Caroline B. F. Mourão and Elisabeth F. Schwartz * \\ Laboratory of Toxinology, Department of Physiological Sciences, University of Brasília, Brasília, \\ DF, 70910-900, Brazil; E-Mail: carolcbfm@gmail.com \\ * Author to whom correspondence should be addressed; E-Mail: efschwa@unb.br; \\ Tel.: +55-61-31073106; Fax: +55-61-31073107.
}

Received: 19 April 2013; in revised form: 28 May 2013 / Accepted: 30 May 2013 /

Published: 14 June 2013

\begin{abstract}
The Kunitz-type protease inhibitors are the best-characterized family of serine protease inhibitors, probably due to their abundance in several organisms. These inhibitors consist of a chain of $\sim 60$ amino acid residues stabilized by three disulfide bridges, and was first observed in the bovine pancreatic trypsin inhibitor (BPTI)-like protease inhibitors, which strongly inhibit trypsin and chymotrypsin. In this review we present the protease inhibitors (PIs) described to date from marine venomous animals, such as from sea anemone extracts and Conus venom, as well as their counterparts in terrestrial venomous animals, such as snakes, scorpions, spiders, Anurans, and Hymenopterans. More emphasis was given to the Kunitz-type inhibitors, once they are found in all these organisms. Their biological sources, specificity against different proteases, and other molecular blanks (being also $\mathrm{K}^{+}$channel blockers) are presented, followed by their molecular diversity. Whereas sea anemone, snakes and other venomous animals present mainly Kunitz-type inhibitors, PIs from Anurans present the major variety in structure length and number of Cys residues, with at least six distinguishable classes. A representative alignment of PIs from these venomous animals shows that, despite eventual differences in Cys assignment, the key-residues for the protease inhibitory activity in all of them occupy similar positions in primary sequence. The key-residues for the $\mathrm{K}^{+}$channel blocking activity was also compared.
\end{abstract}

Keywords: protease inhibitor; Kunitz-type; serine protease; toxin; trypsin; chymotrypsin; venom 


\section{Introduction}

Protease inhibitors (PIs) are proteins or peptides capable of inhibiting the catalytic activity of proteolytic enzymes. They are widely distributed in nature and can be found in all kingdoms of cellular life and also in viral genomes [1,2]. A typical mammalian genome contains $2 \%-4 \%$ of genes encoding for proteases or protease inhibitors, reflecting the importance of proteolysis in their biological processes [3]. PIs have been known since the end of 20th century, and their identification can become more effective nowadays because of the current appliance of protease degradomics [4], which in association with proteomic tools and enzymatic assays can lead to the characterization of innumerous novel protease inhibitors.

Interest in characterizing new PIs and understanding their physiological significance has increased due to their biological relevance for all living processes, such as blood coagulation system, complement cascade, apoptosis, cell cycle and hormone processing pathways [5-8]. Furthermore, deficiencies or alterations in the regulation of these enzymes underlie several pathological conditions, such as cancer, arthritis, neurodegenerative and cardiovascular diseases [9,10].

According to the proteases they inhibit, PIs can be grouped primarily as serine, cysteine, aspartic and metallo protease inhibitors [11]. Among these, serine protease inhibitors are the largest and most widely distributed superfamily of PIs [1,12,13], and based upon their possession of conserved functional motifs they can be subdivided in many classes, being the Kunitz-type inhibitors the best characterized of them, probably due to their abundance in several organisms [2,14-17]. The Kunitz-type motif consists of a polypeptide chain of $\sim 60$ amino acid residues stabilized by three disulfide bridges $\left(\mathrm{C}_{\mathrm{I}}-\mathrm{C}_{\mathrm{VI}}, \mathrm{C}_{\mathrm{II}}-\mathrm{C}_{\mathrm{IV}}, \mathrm{C}_{\mathrm{III}}-\mathrm{C}_{\mathrm{V}}\right)$. The Kunitz-type inhibitors interact with proteases by the classical substrate-like mechanism [13] mainly through the P1-S1 interaction, based on the nomenclature of Schechter and Berger [18]. The standard mechanism implies that substrates/inhibitors contain the reactive site residues $\mathrm{P} 3, \mathrm{P} 2, \mathrm{P} 1, \mathrm{P} 1{ }^{\prime}, \mathrm{P} 2{ }^{\prime}, \mathrm{P} 3$ ', located in the most exposed region of the protease-binding loop, that bind to the substrate amino acid side chains S3, S2, S1, S1', S2', S3', which form the groove or cleft where amide bond hydrolysis occurs. Non-prime and prime designations specify amino- and carboxy-terminal sides of cleavage site, respectively [11,18]. The Kunitz-type motif was first observed in the bovine pancreatic trypsin inhibitor (BPTI)-like protease inhibitors, which strongly inhibit serine proteases such as trypsin and chymotrypsin [19-21].

In this review we present the protease inhibitors described to date from marine venomous animals, most of which have been obtained from sea anemone extracts, but also from Conus species, as well as their counterparts in terrestrial venomous animals, such as snakes, scorpions, spiders, frogs and toads, and bees and wasps. Due to the big amount of data, we have given more emphasis on the Kunitz-type serine protease inhibitors, once they are the most studied compounds among PIs and are found in all these organisms. Initially, the PIs are presented according to their biological sources, together with their main characteristics and activities against different proteases. Then, their dual function including potassium channel blocking activity is discussed, followed by the molecular diversity of protease inhibitor compounds. 


\section{Protease Inhibitors from Sea Anemones}

The first reports on the existence of protease inhibitors in sea anemones species date from the 70 s $[22,23]$. Currently, protease inhibitor peptides and neurotoxins are isolated from sea anemone whole bodies, tentacles, secreted mucus and aggressive organs such as acrorhagi, which is present in some species from Actiniidae family [24].

Several PIs have already been isolated or partially purified and characterized from the sea anemone species Actinia equina [24-26], Anemonia sulcata [27-30], Radianthus koseirensis [31], Heteractis crispa (also named Radianthus macrodactylus) [32-34], Rhodactis rhodostoma [31], Stoichactis sp. [35], Stoichactis helianthus [36-39], Stichodactyla haddoni [40], Anthopleura aff. xanthogrammica [24,41], Anthopleura elegantissima [42] and Anthopleura fuscoviridis [24] (Table 1). Most of these characterized PIs are homologous to Kunitz-type inhibitors. However, some of them belong to different superfamilies.

Table 1. Protease inhibitors from venomous animals. Some protease inhibitors with less information about sequence or biological activity, as well as some putative protease inhibitors only found by means of transcriptomic approach but not tested against proteases, were not included in this table (some of them are found within the text, with the respective UniProtKB code). Organisms from which the PIs were obtained are indicated by the symbols at left: \# sea anemones; + snakes; $\S$ scorpions; $¥$ spiders; $\propto$ Anurans; ø Hymenopterans. Capital letters denote the proteases inhibited: $\mathrm{T}$, trypsin; $\mathrm{C}$, chymotrypsin; CL, cathepsin L; CB, cathepsin B; P, papain; K, kallikrein; PK, plasma kallikrein; TK, tissue kallikrein; Pl, plasmin; E, elastase; $\mathrm{nE}$, neutrophil elastase; $\mathrm{pE}$, pancreatic elastase; X, factor Xa; XII, $\alpha$-factor XIIa; SA, subtilisin A; ptK, proteinase K; Th, thrombin. Structural classes are indicated by symbols: $\downarrow$ Kunitz-type motif protease inhibitors; - Kazal-type protease inhibitors; • thyroglobulin type-1domain; $\diamond$ Ascaris-type motif; $\bigcirc$ Bowman-Birk-type motif.

\begin{tabular}{|c|c|c|c|c|c|c|}
\hline Specie & Toxin & UniProt KB & $\mathbf{A} \mathbf{A}^{a}$ & Protease inhibited & Inhibitory activity $^{\mathrm{b}-\mathrm{g}}$ & References \\
\hline \multirow{4}{*}{ \# Actinia equina } & • AEPI-I & - & $59^{\mathrm{III}}$ & - & - & {$[26]$} \\
\hline & • AEPI-II & - & $59^{\mathrm{III}}$ & - & - & {$[26]$} \\
\hline & - Equistatin & P81439 & $199^{\mathrm{III}}$ & $\begin{array}{l}\text { Cathepsin } \mathrm{L}^{*} \text {, } \\
\text { papain, } \\
\text { cathepsin B }\end{array}$ & $\begin{array}{c}0.051(\mathrm{CL}) \\
0.57(\mathrm{P}) \\
1.4(\mathrm{CB})^{\mathrm{b}}\end{array}$ & {$[25,43]$} \\
\hline & • AEAPI & - & $57^{\text {III }}$ & Trypsin *, plasmin & $700 \mathrm{IU} / \mathrm{mg}(\mathrm{T})^{\mathrm{c}}$ & {$[24]$} \\
\hline \multirow{5}{*}{ \# Anemonia sulcata } & - Elastase inhibitor & P16895 & $48^{\mathrm{III}}$ & Porcine elastase & $1.0^{\mathrm{d}}$ & {$[28,44]$} \\
\hline & - Kalicludin-1 or AsKC1 & Q9TWG0 & $58^{\mathrm{III}}$ & Trypsin & $<30^{d}$ & {$[27]$} \\
\hline & - Kalicludin-2 or AsKC2 & Q9TWF9 & $58^{\mathrm{III}}$ & Trypsin & $<30^{d}$ & {$[27]$} \\
\hline & - Kalicludin-3 or AsKC3 & Q9TWF8 & $59^{\mathrm{III}}$ & Trypsin & $<30^{\mathrm{d}}$ & {$[27]$} \\
\hline & $\diamond$ SA5 II & $\mathrm{P} 10280$ & $62^{\mathrm{III}}$ & Kallikrein, Trypsin & $0.3(\mathrm{~T})^{\mathrm{d}}$ & {$[29,32]$} \\
\hline \multirow{2}{*}{$\begin{array}{l}\text { \# Anthopleura aff. } \\
\text { xanthogrammica }\end{array}$} & • AXPI-I or AXAPI & P81547 & $58^{\text {III }}$ & $\begin{array}{c}\text { Trypsin } * \text {, chymotrypsin, } \\
\text { elastase, thermolysin }\end{array}$ & $1900 \mathrm{IU} / \mathrm{mg}(\mathrm{T})^{\mathrm{c}}$ & {$[24,41]$} \\
\hline & - AXPI-II & P81548 & $58^{\mathrm{III}}$ & Trypsin $*$, chymotrypsin & $490 \mathrm{IU} / \mathrm{mg}(\mathrm{T})^{\mathrm{c}}$ & {$[41]$} \\
\hline
\end{tabular}


Table 1. Cont.

\begin{tabular}{|c|c|c|c|c|c|c|}
\hline \# Anthopleura elegantissima & - APEKTx1 & P86862 & $65^{\text {III }}$ & Trypsin & $124^{\mathrm{d}}$ & {$[42]$} \\
\hline \multirow{2}{*}{ \# Anthopleura fuscoviridis } & - AFAPI-I & - & $56^{\mathrm{III}}$ & Trypsin *, plasmin & $950 \mathrm{IU} / \mathrm{mg}(\mathrm{T})^{\mathrm{d}}$ & [24] \\
\hline & - AFAPI-III & - & $56^{\text {III }}$ & Trypsin *, plasmin & $900 \mathrm{IU} / \mathrm{mg}(\mathrm{T})^{\mathrm{d}}$ & [24] \\
\hline \multirow{3}{*}{ \# Heteractis crispa } & • Jn-IV & P16344 & $56^{\mathrm{III}}$ & Trypsin & $9.6^{\mathrm{d}}$ & {$[32,33]$} \\
\hline & $\bullet \operatorname{InhVJ}$ & - & $56^{\mathrm{III}}$ & $\begin{array}{c}\text { Trypsin *, } \\
\text { chymotrypsin }\end{array}$ & $\begin{array}{l}2.49(\mathrm{~T}) \\
21.7(\mathrm{C})^{\mathrm{d}}\end{array}$ & {$[45-47]$} \\
\hline & - $\mathrm{APHC} 1$ & B2G331 & $56^{\mathrm{III}}$ & $\begin{array}{c}\text { Trypsin, } \\
\text { chymotrypsin }\end{array}$ & $\begin{array}{c}1000(\mathrm{~T}) \\
\sim 5000(\mathrm{C})^{\mathrm{d}}\end{array}$ & [34] \\
\hline \# Rhodactis rhodostoma & Inhibitor 4 & - & $48^{\mathrm{II}}$ & $\begin{array}{c}\text { Trypsin, } \\
\text { kallikrein *, } \\
\text { chymotrypsin }\end{array}$ & $\begin{array}{l}0.95(\mathrm{~T}), \\
0.49(\mathrm{~K}), \\
33(\mathrm{C})^{\mathrm{d}}\end{array}$ & {$[31]$} \\
\hline \# Stichodactyla haddoni & - SHTX-3 & B1B5I8 & $62^{\text {III }}$ & Trypsin & $203 \mathrm{IU} / \mathrm{mg}^{\mathrm{c}}$ & {$[40]$} \\
\hline \multirow[t]{2}{*}{ \# Stoichactis helianthus } & - ShPI-1 & P31713 & $55^{\text {III }}$ & $\begin{array}{c}\text { Serine *, } \\
\text { cysteine, } \\
\text { aspartic proteases }\end{array}$ & $\begin{array}{l}0.11(\mathrm{~T}), \\
2.3(\mathrm{C}), \\
2.7(\mathrm{Pl})^{\mathrm{d}}\end{array}$ & {$[36,37]$} \\
\hline & • ShPI-2 & P81129 & $55^{\text {III }}$ & $\begin{array}{l}\text { Serine, cysteine, } \\
\text { aspartic proteases }\end{array}$ & n.f. & {$[38]$} \\
\hline $\begin{array}{c}+ \text { Dendroaspis polylepis } \\
\text { polylepis }\end{array}$ & - Dendrotoxin E & P00984 & $59^{\mathrm{III}}$ & $\begin{array}{l}\text { Trypsin *, } \\
\text { chymotrypsin }\end{array}$ & $\begin{array}{c}1.0(\mathrm{~T}) \\
100(\mathrm{C})^{\mathrm{d}}\end{array}$ & [48] \\
\hline \multirow{4}{*}{ + Daboia siamensis } & • BBPTI-1 & - & $60^{\mathrm{III}}$ & Chymotrypsin & $4.77^{b}$ & [49] \\
\hline & - CBPTI-1 & A8Y7N4 & $66^{\mathrm{III}}$ & Trypsin & $407^{\mathrm{b}}$ & {$[50]$} \\
\hline & - CBPTI-2 & A8Y7N5 & $60^{\mathrm{III}}$ & Trypsin & $666^{\mathrm{b}}$ & {$[50]$} \\
\hline & - CBPTI-3 & A8Y7N6 & $60^{\mathrm{III}}$ & Chymotrypsin & $2.55^{\mathrm{b}}$ & {$[50]$} \\
\hline + Hemachatus haemachatus & • HHV inhibitor II & P00985 & $57^{\mathrm{III}}$ & $\begin{array}{c}\text { Trypsin, } \\
\text { chymotrypsin, } \\
\text { kallikrein, plasmin }\end{array}$ & - & {$[51]$} \\
\hline + Naja nivea & NNV inhibitor II & P00986 & $57^{\mathrm{III}}$ & Trypsin & - & {$[51]$} \\
\hline \multirow{3}{*}{ + Vipera ammodytes } & - Trypsin inhibitor I & P00991 & $61^{\mathrm{III}}$ & $\begin{array}{c}\text { Trypsin *, } \\
\text { chymotrypsin, } \\
\text { kallikrein, plasmin }\end{array}$ & $\begin{array}{l}0.34(\mathrm{~T}) \\
270(\mathrm{C})^{\mathrm{b}}\end{array}$ & {$[52,53]$} \\
\hline & - Trypsin inhibitor II & - & $62^{\mathrm{III}}$ & $\begin{array}{c}\text { Trypsin *, } \\
\text { chymotrypsin, } \\
\text { kallikrein, plasmin }\end{array}$ & $\begin{array}{l}0.56(\mathrm{~T}) \\
300(\mathrm{C})^{\mathrm{b}}\end{array}$ & {$[52]$} \\
\hline & Chymotrypsin inhibitor & P00992 & $65^{\text {III }}$ & $\begin{array}{l}\text { Chymotrypsin *, } \\
\text { trypsin, } \\
\text { plasma kallikrein }\end{array}$ & $\begin{array}{c}4.3(\mathrm{C}) \\
5100(\mathrm{~T})^{\mathrm{b}}\end{array}$ & {$[52]$} \\
\hline \multirow[b]{2}{*}{+ Bungarus fasciatus } & $\bullet$ BF9 & P25660 & $65^{\text {III }}$ & Chymotrypsin & $58^{\mathrm{d}}$ & {$[54]$} \\
\hline & - Bungaruskunin & B2KTG1 & $59^{\mathrm{III}}$ & $\begin{array}{l}\text { Chymotrypsin *, } \\
\text { trypsin, elastase }\end{array}$ & $6100(\mathrm{C})^{\mathrm{b}}$ & {$[55]$} \\
\hline + Naja naja & - Trypsin inhibitor & P20229 & $57^{\mathrm{III}}$ & Trypsin & $0.0035^{\mathrm{b}}$ & {$[56]$} \\
\hline + Naja atra & - NACI & Q5ZPJ7 & $57^{\mathrm{III}}$ & Chymotrypsin & $25^{\mathrm{b}}$ & {$[57,58]$} \\
\hline \multirow[b]{2}{*}{ + Ophiophagus hannah } & - Oh11-1 & P82966 & $58^{\mathrm{III}}$ & Chymotrypsin & $3520^{\mathrm{b}}$ & {$[59]$} \\
\hline & $\bullet \mathrm{OH}-\mathrm{TCI}$ & B6RLX2 & $58^{\mathrm{III}}$ & $\begin{array}{l}\text { Chymotrypsin *, } \\
\text { trypsin }\end{array}$ & $\begin{array}{l}84.6(\mathrm{C}) \\
391(\mathrm{~T})^{\mathrm{b}}\end{array}$ & {$[60]$} \\
\hline + Bungarus multicinctus & • PILP-1 & B4ESA2 & $58^{\mathrm{III}}$ & Trypsin & $55.62^{\mathrm{b}}$ & [61] \\
\hline
\end{tabular}


Table 1. Cont.

\begin{tabular}{|c|c|c|c|c|c|c|}
\hline $\begin{array}{c}\text { + Oxyuranus scutellatus } \\
\text { scutellatus }\end{array}$ & $\bullet$ TSPI & B7S4N9 & $62^{\mathrm{III}}$ & $\begin{array}{c}\text { Kallikrein *, } \\
\text { trypsin, plasmin, } \\
\text { elastase, factor Xa, } \\
\alpha \text {-factor XIIa }\end{array}$ & $\begin{array}{c}0.057(\mathrm{PK}), \\
0.23(\mathrm{TK}), \\
0.31(\mathrm{~T}), 6.1(\mathrm{Pl}), \\
201(\mathrm{E}), 871(\mathrm{X}), \\
2380(\mathrm{XII})^{\mathrm{b}}\end{array}$ & {$[62,63]$} \\
\hline \multirow{2}{*}{$\begin{array}{c}+ \text { Pseudonaja textilis } \\
\text { textilis }\end{array}$} & - Textilinin-1 & Q90WA1 & $59^{\mathrm{III}}$ & $\begin{array}{l}\text { Plasmin *, } \\
\text { trypsin }\end{array}$ & $\begin{array}{l}0.49 \pm 0.02(\mathrm{Pl}), \\
0.76 \pm 0.02(\mathrm{~T})^{\mathrm{b}}\end{array}$ & {$[7,63]$} \\
\hline & - Textilinin-2 & Q90WA0 & $59^{\mathrm{III}}$ & Plasmin & $2.2^{\mathrm{b}}$ & {$[7]$} \\
\hline $\begin{array}{c}\text { + Macrovipera lebetina } \\
\text { transmediterranea }\end{array}$ & • PIVL & I2G9B4 & $67^{\mathrm{III}}$ & Trypsin & - & [64] \\
\hline \multirow{3}{*}{ + Pseudechis australis } & - Pr-mulgin 1 & E7FL11 & $59^{\mathrm{III}}$ & Metalloprotease 2 & $60^{\mathrm{b}}$ & {$[65]$} \\
\hline & - Pr-mulgin 2 & E7FL12 & $59^{\mathrm{III}}$ & $\begin{array}{c}\text { Trypsin *, } \\
\text { chymotrypsin, } \\
\text { plasmin }\end{array}$ & $\begin{array}{c}5(\mathrm{~T}), \\
40(\mathrm{C}), \\
40(\mathrm{Pl})^{\mathrm{b}}\end{array}$ & {$[65]$} \\
\hline & - Pr-mulgin 3 & E7FL13 & $59^{\text {III }}$ & $\begin{array}{l}\text { Trypsin, } \\
\text { plasmin }\end{array}$ & $\begin{array}{c}5(\mathrm{~T}) \\
100(\mathrm{Pl})^{\mathrm{b}}\end{array}$ & {$[65]$} \\
\hline$\S$ Mesobuthus tamulus & - Fraction IX-1-a & - & - & $\begin{array}{l}\text { Trypsin *, } \\
\text { kallikrein }\end{array}$ & $\begin{array}{l}19.2 \mathrm{IU} / \mathrm{mg}(\mathrm{T}), \\
87 \mathrm{IU} / \mathrm{mg}(\mathrm{K})^{\mathrm{c}}\end{array}$ & [66] \\
\hline$\S$ Hadrurus gertschi & $\diamond \mathrm{rHg} 1$ & P0C8W3 & $67^{\mathrm{III}}$ & Trypsin & $107^{\mathrm{d}}$ & {$[67,68]$} \\
\hline \multirow{3}{*}{$\S$ Lychas mucronatus } & - rLmKTT-1a & P0DJ46 & $59^{\mathrm{III}}$ & Trypsin & $140^{\mathrm{d}}$ & {$[16,68]$} \\
\hline & - rLmKTT-1b or SdPI & P0DJ45 & $59^{\mathrm{III}}$ & Trypsin & $160^{\mathrm{d}}$ & {$[16,68]$} \\
\hline & - rLmKTT-1c & P0DJ48 & $59^{\mathrm{III}}$ & Trypsin & $124^{\mathrm{d}}$ & {$[68]$} \\
\hline \multirow{3}{*}{$\S$ Mesobuthus martensii } & - rBmKTT-1 & P0DJ49 & $59^{\mathrm{III}}$ & Trypsin & $136^{\mathrm{d}}$ & {$[68]$} \\
\hline & - rBmKTT-2 & P0DJ50 & $58^{\mathrm{IV}}$ & Trypsin & $420^{d}$ & {$[68]$} \\
\hline & - rBmKTT-3 & P0DJ47 & $70^{\mathrm{III}}$ & Trypsin & $760^{d}$ & {$[68]$} \\
\hline$\S$ Scorpiops jendeki & $\diamond \mathrm{rSjAPI}$ & - & $64^{\mathrm{v}}$ & $\begin{array}{c}\text { Chymotrypsin *, } \\
\text { elastase }\end{array}$ & $\begin{array}{l}97.1(\mathrm{C}) \\
3700(\mathrm{E})^{\mathrm{b}}\end{array}$ & [69] \\
\hline$¥$ Ornithoctonus huwena & • HWTX-XI & P68425 & $55^{\mathrm{III}}$ & Trypsin & $0.23^{\mathrm{d}}$ & [14] \\
\hline \multirow[b]{2}{*}{$¥$ Araneus ventricosus } & - AvKTI & K7YYJ2 & $57^{\mathrm{III}}$ & $\begin{array}{c}\text { Trypsin, } \\
\text { chymotrypsin, } \\
\text { plasmin *, } \\
\text { neutrophil elastase }\end{array}$ & $\begin{array}{c}7.34(\mathrm{~T}), \\
37.75(\mathrm{C}), \\
4.89(\mathrm{Pl}), \\
169.07(\mathrm{E})^{\mathrm{b}}\end{array}$ & [70] \\
\hline & - $\mathrm{AvCI}$ & L7X735 & $70^{\mathrm{IV}}$ & $\begin{array}{c}\text { Chymotrypsin, } \\
\text { subtilisin A, } \\
\text { proteinase K, } \\
\text { neutrophil elastase, } \\
\text { pancreatic elastase }\end{array}$ & $\begin{array}{c}49.85(\mathrm{C}), \\
20.51(\mathrm{SA}), \\
65.42(\mathrm{ptK}), \\
8.74(\mathrm{nE}) \\
11.32(\mathrm{pE})^{\mathrm{b}} \\
\end{array}$ & [71] \\
\hline a Bombina bombina & $\diamond \mathrm{BSTI}$ & Q90248 & $60^{\mathrm{V}}$ & $\begin{array}{l}\text { Trypsin, } \\
\text { thrombin }\end{array}$ & $\begin{array}{l}80-100(\mathrm{~T}) \\
1300(\mathrm{Th})^{\mathrm{b}}\end{array}$ & [72] \\
\hline a Bombina maxima & $\diamond \mathrm{BMTI}$ & Q8QFP3 & $60^{\mathrm{v}}$ & Trypsin & $60^{\mathrm{b}}$ & [73] \\
\hline a Rana areolata & $\diamond$ Trypsin inhibitor & - & $61^{\mathrm{v}}$ & Trypsin & $\sim 20,000^{\mathrm{e}}$ & {$[74]$} \\
\hline a Bombina orientalis & $\diamond \mathrm{BOTI}$ & Q800F0 & $60^{\mathrm{V}}$ & - & - & {$[75]$} \\
\hline a Bombina variegata & $\diamond \mathrm{BVTI}$ & Q800E9 & $60^{\mathrm{v}}$ & - & - & {$[75]$} \\
\hline Bombina & $\diamond$ BMSI 1 & $\mathrm{~B} 1 \mathrm{P} 2 \mathrm{~F} 8$ & $60^{\mathrm{V}}$ & Trypsin, thrombin & $20(\mathrm{~T}), 150(\mathrm{Th})^{\mathrm{b}}$ & {$[76]$} \\
\hline microdeladigitora & $\diamond \mathrm{BMSI} 2$ & B1P2F9 & $60^{\mathrm{v}}$ & - & - & {$[76]$} \\
\hline
\end{tabular}


Table 1. Cont.

\begin{tabular}{|c|c|c|c|c|c|c|}
\hline \multirow[t]{2}{*}{ a Hyla simplex } & Hylaserpin S1 & H6SWK9 & 392 & $\begin{array}{c}\text { Trypsin, } \\
\text { chymotrypsin }\end{array}$ & $\begin{array}{c}55(\mathrm{~T}), \\
310(\mathrm{C})^{\mathrm{b}}\end{array}$ & {$[77]$} \\
\hline & $\diamond$ Hylaserpin S2 & H6SWL0 & $56^{\mathrm{V}}$ & Trypsin & $72^{b}$ & {$[77]$} \\
\hline \multirow[b]{2}{*}{ a Bufo andrewsi } & BATI & - & - & Trypsin & $14^{\mathrm{b}}$ & {$[78]$} \\
\hline & Baserpin & - & - & $\begin{array}{c}\text { Trypsin, } \\
\text { chymotrypsin, } \\
\text { elastase }\end{array}$ & $\begin{array}{l}4.6 \times 10^{6}(\mathrm{~T}) \\
8.9 \times 10^{6}(\mathrm{C}) \\
6.8 \times 10^{6}(\mathrm{E})^{\mathrm{f}}\end{array}$ & [79] \\
\hline Kaloula pulchra hainana & KPHTI & - & - & Trypsin & $27^{\mathrm{c}}$ & [80] \\
\hline \multirow{2}{*}{ a Phyllomedusa sauvagii } & - PSKP-1 & P83578 & $58^{\mathrm{III}}$ & Prolyl endopeptidase & $124 \pm 56^{\mathrm{g}}$ & {$[81]$} \\
\hline & - PSKP-2 & P83579 & $58^{\mathrm{III}}$ & - & - & [81] \\
\hline \multirow{3}{*}{ a Phyllomedusa nordestina } & PI01 & K9N0E2 & $78^{\mathrm{III}}$ & - & - & {$[82]$} \\
\hline & $\mathrm{PI02}$ & K9N1K5 & $77^{\mathrm{III}}$ & - & - & {$[82]$} \\
\hline & $\mathrm{PI03}$ & K9N2T9 & $53^{\mathrm{III}}$ & - & - & {$[82]$} \\
\hline a Agalychnis callidryas & - ACKTI & I7J523 & $52^{\mathrm{III}}$ & Trypsin & $1.9^{\mathrm{b}}$ & [83] \\
\hline ๔ Dyscophus guineti & - Kunitz-type PI & J9UVV9 & $57^{\mathrm{III}}$ & Trypsin & - & [17] \\
\hline a Kassina senegalensis & $\bullet \mathrm{KSCI}$ & F8K9Q3 & $62^{\mathrm{III}}$ & Chymotrypsin & - & [84] \\
\hline a Hyla annectans & Anntoxin & C7AR58 & $60^{\mathrm{II}}$ & Trypsin & $25^{b}$ & [85] \\
\hline a Odorrana grahami & OGTI & - & $17^{\mathrm{II}}$ & Trypsin & $400^{\mathrm{b}}$ & {$[86]$} \\
\hline a Huia versabilis & HV-BBI & B1VC43 & $18^{\mathrm{I}}$ & Trypsin & $18.8+1.8^{\mathrm{b}}$ & [87] \\
\hline$\varnothing$ Vespa bicolor Fabricius & - Bicolin & C0LNR2 & $54^{\mathrm{III}}$ & Trypsin $*$, thrombin & $550(\mathrm{~T}), 26,000(\mathrm{Th})^{\mathrm{b}}$ & [88] \\
\hline$\varnothing$ Bombus ignitus & • Bi-KTI & G3LH89 & $58^{\mathrm{III}}$ & Plasmin & $43.53^{\mathrm{g}}, 3.6^{\mathrm{b}}$ & {$[6]$} \\
\hline$ø$ Bombus terrestris & • Bt-KTI & D8KY58 & $58^{\mathrm{III}}$ & Plasmin & $2.01^{\mathrm{b}}$ & [89] \\
\hline \multicolumn{7}{|c|}{ 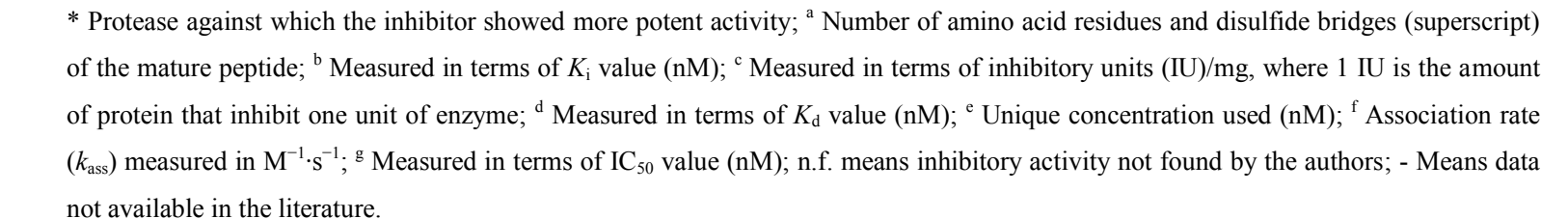 } \\
\hline
\end{tabular}

Equistatin, a protease inhibitor isolated from the hydrophilic extract of the whole body of Actinia equina [25], is an acidic protein composed of three thyroglobulin type-1 domains [43]. It is encoded by a putative sequence of 231 amino acids, including the signal peptide [43]. Equistatin inhibits papain-like cysteine proteases, such as papain and cathepsin L, with lower affinity for cathepsin B (Table 1) [25]. It was further shown that the $N$-terminal domain alone acts as a Cys protease inhibitor ( $K_{\mathrm{i}}$ of $0.6 \mathrm{nM}$ for papain), and the second domain act as an aspartic protease inhibitor $\left(K_{\mathrm{i}}\right.$ of 0.3 for cathepsin D). The function of the third domains remains unknown [90,91].

From the extracts of Anemonia sulcata it was isolated an elastase inhibitor (AEI) that was found to be a non-classical Kazal-type inhibitor with respect to positioning of the cysteine residues $[28,30,44]$. With 48 amino acid residues, its tridimensional structure resembles those of typical Kazal-type inhibitors, however, the disulfide bridge $\mathrm{C}_{\mathrm{I}}-\mathrm{C}_{\mathrm{V}}$ in the sea anemone elastase inhibitor is shifted by one turn in the $\alpha$-helical segment towards the $C$-terminal in comparison with those of Kazal-type's [28,30]. The inhibitor strongly inhibits porcine pancreatic elastase (Table 1), with weaker activity against human leucocytes elastase $\left(K_{\mathrm{i}}\right.$ of $\left.1.0 \mu \mathrm{M}\right)$. No inhibition was observed against other serine proteases such as bovine trypsin, bovine chymotrypsin, subtilisin from Bacillus subtilis and cathepsin $\mathrm{G}$ from human leucocytes [44]. 
Type II toxins from sea anemone are a peptide group that block $\mathrm{K}_{\mathrm{v}} 1$ channel currents - although with much less potency than the sea anemone type $\mathrm{I}$ toxins, which are potent $\mathrm{K}_{\mathrm{v}} 1$ channel blockers [92] — and are characterized by a polypeptide chain of 58-63 amino acid residues and three disulfide bridges $[42,93]$. They are homologous to Kunitz-type inhibitors of serine proteases and their biological role is still unclear. It is supposed that these protease inhibitors could (1) defend sea anemones from the protease of their victims; (2) protect the toxins injected into preys or predators from fast degradation; (3) act on the regulation of digestive mechanisms, including self-digestion by their own enzymes or by those of symbiotic microorganism; (4) and also, due to their dual activity, they could also be used to paralyze preys $[31,35,92]$.

Among these Kunitz-type inhibitor toxins (KTTs), the sea anemone kalicludines (AsKC1 to AsKC3, Table 1), from Anemonia sulcata, are examples of toxins with both protease inhibitor and potassium channel blocking activities (Table 2) [27]. With 58-59 amino acid residues cross-linked by three disulfide bridges, all the three kalicludines inhibit trypsin with very similar inhibition profiles, in a 1:1 molar ratio, such as BPTI. From titration curves $K_{\mathrm{d}}$ values below $30 \mathrm{nM}$ could be deduced [27]. Another KTT from A. sulcata is the Kunitz-type protease inhibitor 5 II (SA5 II, Table 1), which inhibits both tissue and plasma kallikreins [29]. Previous to these studies, at least ten KTTs with inhibitory effects against trypsin, chymotrypsin, plasmin and kallikrein have been reported from A. sulcata extracts [22,23].

Table 2. Potassium channel blocking activity of Kunitz-type motif protease inhibitor peptides from animal venoms. Scorpion and spider mutated peptides were not considered.

\begin{tabular}{|c|c|c|c|c|}
\hline Source & Peptide & $\mathrm{IC}_{50}(\mathrm{nM})$ & Target & Ref. \\
\hline \multirow{5}{*}{ Sea anemone } & APEKTx $1 *$ & $0.9 \pm 0.1$ & $\mathrm{~K}_{\mathrm{v}} 1.1$ & {$[42]$} \\
\hline & AsKC1 * & 2800 & $\mathrm{~K}_{\mathrm{v}} 1.2$ & {$[27]$} \\
\hline & $\mathrm{AsKC} 2 *$ & 1100 & $\mathrm{~K}_{\mathrm{v}} 1.2$ & [27] \\
\hline & AsKC3 * & 1300 & $\mathrm{~K}_{\mathrm{v}} 1.2$ & {$[27]$} \\
\hline & SHTX-3 $*$ & 650 & Synap ${ }^{a}$ & {$[40]$} \\
\hline \multirow[t]{3}{*}{ Cone snail } & Conk-S1 & $1.33 \pm 0.5$ & Shaker & {$[94]$} \\
\hline & $\alpha-\mathrm{DTX}$ & $0.4-150$ & $\mathrm{~K}_{\mathrm{v}} 1.1, \mathrm{~K}_{\mathrm{v}} 1.2, \mathrm{~K}_{\mathrm{v}} 1.6$ & [95] \\
\hline & DTX-I & $0.13-50$ & $\mathrm{~K}_{\mathrm{v}} 1.1, \mathrm{~K}_{\mathrm{v}} 1.2, \mathrm{~K}_{\mathrm{v}} 1.6$ & [95] \\
\hline \multirow[t]{6}{*}{ Snake } & DTX-K & 0.03 & $\mathrm{~K}_{\mathrm{v}} 1.1$ & {$[96]$} \\
\hline & $\delta$-DTX & $0.029-1.8$ & $\mathrm{~K}_{\mathrm{v}} 1.1$ & {$[96,97]$} \\
\hline & $\mathrm{DaE}$ & 300 & $\mathrm{~K}_{\mathrm{v}} 1.1$ & [98] \\
\hline & $\operatorname{Hg} 1 *$ & $6.2 \pm 1.2$ & $\mathrm{~K}_{\mathrm{v}} 1.3$ & {$[68]$} \\
\hline & LmKTT-1a* & 1580 & $\mathrm{~K}_{\mathrm{v}} 1.3$ & {$[68,99]$} \\
\hline & LmKTT-1b * & $>1000$ & $\mathrm{~K}_{\mathrm{v}} 1.3$ & [68] \\
\hline \multirow[t]{4}{*}{ Scorpion } & LmKTT-1c * & $>1000$ & $\mathrm{~K}_{\mathrm{v}} 1.3$ & {$[68]$} \\
\hline & BmKTT-1 * & $129.7 \pm 31.3$ & $\mathrm{~K}_{\mathrm{v}} 1.3$ & {$[68]$} \\
\hline & BmKTT-2 * & $371.3 \pm 82.1$ & $\mathrm{~K}_{\mathrm{v}} 1.3$ & {$[68]$} \\
\hline & BmKTT-3 * & $>1000$ & $\mathrm{~K}_{\mathrm{v}} 1.3$ & {$[68]$} \\
\hline Spider & HWTX-XI * & 2570 & $\mathrm{~K}_{\mathrm{v}} 1.1$ & [14] \\
\hline
\end{tabular}

* Peptides that also present protease inhibitory activity, as shown in Table 1; ${ }^{a}$ Activity obtained through synaptosomal binding assay. 
In the $80 \mathrm{~s}$, three protease inhibitors composed of 52-56 amino acid residues were isolated from Stoichactis sp. [35]. Inhibitors 2 and 3 had estimated molecular masses of $\sim 6000$ Da. Inhibitor 2, which was the main component, had its approximate molecular mass (5800 Da) determined by gel filtration. Inhibitors 2 and 3 lack tryptophan in their structures and contain two and three disulfide bridges, respectively. They both inhibited trypsin almost completely (98\%) and, to a lesser extent, also chymotrypsin (86\% and 92\%, respectively). Inhibitor 1, which was still impure, presented a lower inhibitory activity ( $80 \%$ against trypsin and $50 \%$ against chymotrypsin).

In the same decade, protease inhibitors were isolated from the body extracts of Radianthus koseirensis and Rhodactis rhodostoma [31]. From R. rhodostoma, the main protease inhibitor has $5459 \mathrm{Da}$ and only two disulfide bridges. Named inhibitor 4 (Table 1), it had a high affinity for serine proteases (trypsin, kallikrein and chymotrypsin), and was less active in terms of the molar ratio (enzyme:inhibitor). Whereas typical trypsin inhibitors act stoichiometrically 1:1, inhibitor 4 from R. rhodostoma had a ratio of 1:2 for trypsin and 1:2.4 for chymotrypsin and kallikrein. From R. koseirensis, an inhibitor fraction was obtained, but it had very low affinity for serine proteases and did not inhibit chymotrypsin. The authors suggest that the ineffectiveness towards serine proteases of R. koseirensis fraction may have its origin in the neutral to slightly acidic properties of its inhibitor molecule. Differently, PIs from $R$. rhodostoma are basic in nature, such as BPTI and many KTTs [31].

Until now, many PIs were isolated from the body extract of Heteractis crispa (=Radianthus macrodactylus), but only few of them were fully characterized. Protease inhibitors of about $6000 \mathrm{Da}$ were obtained from a water-ethanol extract of H. crispa, and the primary structure was elucidated for one of them, named Kunitz-type trypsin inhibitor IV or Jn-IV (Table 1) [33]. After that, four trypsin inhibitors were isolated (InI-InIV), and one of them (InI) was partially characterized. Composed by 59 amino acid residues, its molecular mass determined by SDS-PAGE was 7100 Da, whereas its molecular mass calculated by the amino acid composition was $6304 \mathrm{Da}$ [100]. Posteriorly, two serine protease inhibitors were isolated [32]. RmIn I and RmIn II have 6322.8 and 6096.0 Da, respectively, according to their amino acid composition, and both have three disulfide bridges and no methionine or tryptophan residues [32], which is common in Kunitz-type protease inhibitors [35,51,101], with few exceptions (Figure 1). The $N$-terminal amino acid sequences of RmIn I and RmIn II were determined and they were $66 \%-86 \%$ identical with the analogous fragment of Kunitz-type trypsin inhibitor IV, isolated from the same source, suggesting that they are isoforms. Both RmIn I and RmIn II were active against trypsin and $\alpha$-chymotrypsin, with $K_{\mathrm{i}}$ values of 2.4 and $2.5 \mathrm{nM}$ for trypsin and 23 and $30 \mathrm{nM}$ for $\alpha$-chymotrypsin, respectively. Moreover, both polypeptides were not toxic to mice $(10-100 \mu \mathrm{g}$ of peptide per kg of animal) and exhibited antihistamine activity in a dose-dependent manner [32].

Also from Heteractis crispa extract, a Kunitz-type toxin designated as InhVJ was isolated (Table 1) [45,46]. It has $6106 \mathrm{Da}$, three disulfide bridges and also no Met or Trp residues [45,47]. Its putative sequence encodes a 78-amino acid residues polypeptide, including a signal peptide with 22 amino acid residues [47]. InhVJ is highly specific toward trypsin and $\alpha$-chymotrypsin and did not inhibit other serine proteases (such as thrombin, kallikrein and plasmin), neither cysteine (papain) nor aspartic (pepsin) proteases [45,46]. Recently characterized, the analgesic polypeptide HC1 (or APHC1), with 6187.0 Da, presents very weak inhibition against trypsin and chymotrypsin (Table 1), although it completely inhibits both at a 1:1 molar ratio. Its main activity is related to an analgesic effect due to modulation of mammalian TRPV1-receptors [34]. 
The peptides ShPI-1 and ShPI-2 were obtained from the crude extract of Stoichactis helianthus. With 6110.6 Da and six cysteine residues, ShPI-1 was active against many proteases of different mechanistic classes [37]. It inhibited serine, cysteine and aspartic proteases, and did not affect the one metalloenzyme tested (bacterial collagenase). The strongest inhibition capacity was against trypsin $\left(K_{\mathrm{i}}=1.1 \times 10^{-10} \mathrm{M}\right)$. Other serine proteases such as plasmin and chymotrypsin, and cysteine proteases (bromelain and papain) were inhibited with smaller intensity. The smallest degrees of inhibition were obtained against the serine protease kallikrein and elastase and against aspartic proteases [37].

Four serine protease inhibitors (AEPI-I to -IV) were isolated from the sea anemone Actinia equina [26]. Whereas only 35 and $37 \mathrm{~N}$-terminal amino acid residues were determined for AEPI-III and -IV, the complete primary sequence was determined to AEPI-I and -II, which contain 59 amino acid residues and three disulfide bonds. Both peptides (Table 1) share structural similarity with Kunitz-type inhibitors, however, their protease inhibitory activity has not been measured yet.

From the whole body extract of Stichodactyla haddoni, four peptide toxins were isolated and named SHTX-1 to SHTX-4 [40]. SHTX-1-3 induced paralysis in crabs with $\mathrm{ED}_{50}$ values of 430, 430 and $183 \mu \mathrm{g} / \mathrm{kg}$, respectively, exhibiting no lethality even at $1000 \mu \mathrm{g} / \mathrm{kg}$. SHTX-4 was lethal to crab with an estimated $\mathrm{LD}_{50}$ of $93 \mu \mathrm{g} / \mathrm{kg}$. Among them, SHTX-3 was the only one with an antitryptic activity (Table 1), as well as potassium channel blocking activity (Table 2). SHTX-3 toxin has 7035.0 Da and is cross-linked by three disulfide bridges. Its cloned gene encodes a putative sequence of 19 amino acid residues for the signal peptide and 62 for the mature peptide, without a propart between them. Because it was previously proposed that the propart with two basic residues at its end functions as a signal directing toxins into nematocyst [102], it is assumed that SHTX III is not contained in these stinging cnidarian organelles [40].

AXPI-I and -II (Table 1) were isolated from the whole body extract of Anthopleura aff. xanthogrammica [41]. Both are basic peptides, with three disulfide bonds, 58 amino acid residues and belong to the Kunitz-type family. Both inhibited trypsin at a molar ratio of 2:1 (inhibitor: enzyme). AXPI-I was moderately or weakly inhibitory against the serine proteases $\alpha$-chymotrypsin and elastase, and against the metallo-proteases thermolysin and Streptomyces griseus protease. AXPI-II also presented weak inhibition against $\alpha$-chymotrypsin. Neither of them inhibited the cysteine proteases papain nor bromelain [41].

AXAPI, which was another name given to AXPI-I (Table 1), was further isolated from the acrorhagial extract of this same species [24]. Since much higher protease inhibitory activity was displayed by the acrorhagi of $A$. aff. xanthogrammica (59 IU/mL) than the remaining tissues (2.9 IU/mL), the authors suggested that AXPI-I is derived from the acrorhagi. Competitive inhibition experiments with ${ }^{125} \mathrm{I}-\alpha$-dendrotoxin and rat synaptosomal membranes suggest that this peptide has no potassium channel toxicity even at $10 \mu \mathrm{M}$ [24]. In the same study, two Kunitz-type PIs that were purified from the acrorhagial extracts of Anthopleura fuscoviridis (AFAPI-I and AFAPI-III, Table 1) and one from Actinia equina (AEAPI, Table 1) were also described [24]. Similar to AXAPI, they all inhibited both trypsin and plasmin and did not inhibit potassium channels at the same concentration [24].

The toxin APEKTx1 was isolated from Anthopleura elegantissima and is slightly larger than most of the KTTs (Table 1) [42]. With 63 amino acid residues, 7468.5 Da and three disulfide bridges, this toxin inhibits serine proteases and also blocks potassium channels (Table 2), similar to the kalicludines 
and SHTX-3 [27,40]. APEKTx1 is presumably a competitive trypsin inhibitor, with a dissociation constant $\left(K_{\mathrm{d}}\right)$ of $124 \mathrm{nM}$. However, a 3-fold molecular excess of toxin over trypsin was needed to completely inhibit the protease, which is about 3 times the amount of BPTI or the kalicludines necessary to reach total trypsin inhibition [42].

\section{PIs from Conus Venoms}

Conotoxins are small disulfide-rich peptide toxins from cone snails usually with 10-30 amino acid residues that have evolved from at least 16 genetically distinct superfamilies, many of which are subject to diverse types of posttranslational modifications, such as $C$-terminal amidation, hydroxyprolines, or glycosylation of serine or threonine [103,104]. They can be divided into several families according to the cysteine bridge pattern and biological activities [104]. In relation to most of Conus venom toxins, conkunitzin-S1 (Conk-S1, UniProtKB P0C1X2), from the venom of Conus striatus, is unusually long (60 amino acid residues) and has a $C$-terminal amidation as the only posttranslational modification [105]. This potassium channel pore-blocking polypeptide (Table 2) also belongs to the Kunitz-type inhibitor domain, although it is stabilized by only two of the three disulfide bridges normally found in KTTs [105].

The cDNA library constructed with the mRNA from Conus californicus venom ducts revealed the presence of four new putative Kunitz-type inhibitors (Ca19.1a to Ca19.1d, UniProtKB D2Y488, D2Y489, D2Y490 and D2Y491, respectively) [106]. The mature peptides of these four compounds have 56 amino acid residues and share high sequence identity. Despite having about the same length of the Conk-S1, these toxins have six cysteine residues. Their activity as protease inhibitors is still uncertain [106]. In addition, another putative Kunitz-type inhibitor (conkunitzin-B1, UniProtKB P0CY85) was obtained from the transcriptome of Conus bullatus venom ducts by means of next-generation sequencing techniques [107].

\section{PIs from Terrestrial Venomous Animals}

\subsection{PIs from Snake Venoms}

Similar to those from marine venomous animals, most of protease inhibitors characterized so far from snake venoms present the Kunitz-type motif. These snake venom polypeptides have been demonstrated to specifically inhibit the proteolytic activity of trypsin or chymotrypsin. However, some snake neurotoxins, such as dendrotoxins, calcicludine and B chain of $\beta$-bungarotoxin, possess a Kunitz/BPTI-like domain although they exhibit little or no protease inhibitory activity.

In the beginning of 70's, from the venom of the black mamba (Dendroaspis polylepis polylepis), the first trypsin inhibitor homologs (toxins I and K) were reported [108]. Related toxins containing 57-60 amino acid residues and cross-linked by three disulfide bridges were subsequently characterized from different mamba venoms and eventually named dendrotoxins (DTXs), such as the $\alpha$-dendrotoxin from the green mamba snake (Dendroaspis angusticeps) [95,109]. Dendrotoxins are potent blockers of certain subtypes of voltage-gated potassium channels (Table 2) [95,110]. Differently from toxins I and $\mathrm{K}$, dendrotoxin $\mathrm{E}$, from black mamba, was shown to inhibit both trypsin and chymotrypsin (Table 1) [48]. 
Also from Dendroaspis angusticeps, calcicludine (CaC, UniProtKB P81658) is a 60-amino acid residue polypeptide that does not display protease inhibitory activity either $\mathrm{K}^{+}$or $\mathrm{Na}^{+}$channel modulator activities. $\mathrm{CaC}$ specifically blocks most of the high-threshold $\mathrm{Ca}^{2+}$ channels in the nanomolar range, specially the L-type component of the $\mathrm{Ca}^{2+}$ current [111,112]. $\beta$-Bungarotoxin was previously isolated from Bungarus multicinctus venom and comprises two dissimilar polypeptide chains, the A chain $(\sim 14 \mathrm{kDa})$ and $\mathrm{B}$ chain $(\sim 7 \mathrm{kDa})$, which are linked by an interchain disulfide bridge [113]. The $\mathrm{B}$ chain of $\beta$-bungarotoxin is homologous to venom basic protease inhibitors but, similar to most of dendrotoxins, displays no protease inhibitory activity and also blocks voltage-gated $\mathrm{K}^{+}$channels [114].

Despite the dendrotoxin related toxins, several Kunitz-type protease inhibitors have been isolated from snake venoms, particularly from Elapidae and Viperidae snakes. The Russell's viper venom (RVV) inhibitor, from Daboia russelii (=Vipera russelli), seems to be the first of them [101]. It is a basic polypeptide with deduced 60 amino acid residues and inhibitory activity against plasma and pancreatic kallikreins, plasmin and trypsin, being more potent against trypsin. A Kunitz-type inhibitor homolog (RVV inhibitor II, UniProtKB P00990) was further sequenced from the venom of the Eastern Russel's viper (=Daboia siamensis) [115]. Recently, similar polypeptides were identified in the venom of Daboia siamensis [49,50]. From the Burmese specie, BBPTI-1 (Table 1) was shown to strongly inhibit chymotrypsin activity, with no detectable inhibitory activity against trypsin [49]. From the Chinese one, two trypsin inhibitors (CBPTI-1 and CBPTI-2, Table 1) and one chymotrypsin inhibitor (CBPTI-3, Table 1) were purified and cloned [50].

Five PIs were isolated from the venoms of the African Elapids Hemachatus haemachatus and Naja nivea [51]. The isolated trypsin inhibitors have 52 to 57 amino acid residues, and were all devoid of tryptophan. Except for one peptide from Naja nivea venom, designated NNV inhibitor la, which had two disulfide bonds, all the others contained three. Two high homologous peptides (HHV inhibitor II and NNV inhibitor II, Table 1) were completely sequenced. Similar to HHV inhibitor I, HHV inhibitor II was active against trypsin, $\alpha$-chymotrypsin, plasma kallikreins and plasmin from bovine sources. NNV inhibitor II was only tested against trypsin.

From the venom of the long-nosed viper Vipera ammodytes, three basic PIs were isolated [52]. Two of them strongly inhibit trypsin, whereas the third one primarily inhibits chymotrypsin (Table 1). Other enzymes were also inhibited, although with lower potency. The precursors of the chymotrypsin inhibitor and trypsin inhibitor I were further obtained [116]. An homologous putative trypsin inhibitor was also sequenced from the venom of the leaf-nosed viper, Eristicophis macmahoni (UniProtKB P24541) [117].

Until now, two PIs have been isolated from Bungarus fasciatus venom [54,55]. The first of them was denoted protease inhibitor IX (or BF9, Table 1) and consists of a polypeptide chain of 65 amino acid residues that, when cleaved, generates the protease inhibitor VIIIb [54]. BF9 specifically inhibits $\alpha$-chymotrypsin in a 1:1 molar ratio and is structurally similar to the Kunitz-type toxins [54,118]. The second is a Kunitz-type serine protease inhibitor named bungaruskunin (Table 1), which was characterized from venom and also cloned from venom glands [55]. The predicted precursor contains 83 amino acid residues, including a 24-residues long signal peptide. The mature bungaruskunin inhibits trypsin, chymotrypsin, and elastase, but not thrombin. 
From the venom of the cobra Naja naja, a strong trypsin inhibitor (Table 1) [56] and a putative 57-amino acid residue chymotrypsin inhibitor (UniProtKB P19859) were characterized [119]. With almost $90 \%$ identity to the latter, a chymotrypsin inhibitor was also characterized from the venom of Naja atra (NACI, Table 1) [57]. No detectable inhibitory effects were observed on trypsin or plasmin. Its precursor was further characterized and it was shown that the expressed protein without the first three residues at its $N$-terminal led to a moderate increase in the inhibitory constant against chymotrypsin [58].

A weak chymotrypsin inhibitor with no inhibitory action against trypsin was characterized from the venom of the king cobra Ophiophagus hannah (Oh11-1, Table 1) [59]. After that, a peptide named $\mathrm{OH}-\mathrm{TCI}$ was shown to inhibit both chymotrypsin and trypsin with similar potencies [60]. The inhibition constants of the native peptide for chymotrypsin and trypsin were both around $170 \mathrm{nM}$, while the recombinant peptide presented no more than 5-fold difference between both values (Table 1). No detectable effects were observed against thrombin and subtilisin [60].

The structural organization of the genes encoding three protease inhibitor-like proteins (PILP-1 to PILP-3) from Bungarus multicinctus was reported [61]. Recombinant PILP-1 inhibited trypsin (Table 1), whereas PILP-2 (UniProtKB B4ESA3) and PILP-3 (UniProtKB B4ESA4) did not inhibit chymotrypsin or trypsin. PILP genes share identical organization with B chain genes, with three exons interrupted by two introns in similar positions. Comparative analysis of PILP and B chain genes, together with the high degree of sequence similarity of the polypeptides, suggested that these genes have originated from a common ancestor and that they should be evolved by gene duplication followed by divergence [61].

Two distinct types of KTTs have already been characterized from the venom of Australian elapid snakes. Taicatoxin serine protease inhibitor (TSPI, Table 1) was purified from the venom of Oxyuranus scutellatus scutellatus as part of a multimeric complex that blocks high threshold calcium channels and small conductance $\mathrm{Ca}^{2+}$-activated $\mathrm{K}^{+}$channels $[62,120] . \mathrm{In}$ its isolated form, TSPI exhibits antifibrinolytic activity and is a broad spectrum inhibitor, being active against plasma and tissue kallikrein, trypsin, elastase, factor Xa, and $\alpha$-factor XIIa [62,63]. Subsequently, a second family of Kunitz-type inhibitors was purified, cloned and characterized from the venom of the common brown snake Pseudonaja textilis [7,121]. Two of them, textilinin-1 and -2 (Table 1), were shown to be potent plasmin inhibitors [7,63]. Textilinin-1 is also a potent trypsin inhibitor, with little effect on both plasma and tissue kallikrein, and no effect on many other proteases tested $[63,122]$. Because textilin-1 has been shown to inhibit plasmin and reduce bleeding in a small animal model [7], further studies have suggested its use as a therapeutic alternative for aprotinin [122,123], which is widely used in surgery as an anti-bleeding agent but is associated with numerous side effects [124].

From the New Guinean Pseudechis australis (=Pseudechis rossignolii), three cDNAs encoding Kunitz-type protease inhibitors were isolated and named Pr-mulgins 1, 2 and 3 [65]. The putative polypeptides are 92.4\%-99.3\% identical with their orthologs in the Australian Pseudechis australis [125]. Recombinant Pr-mulgin 1 significantly affected matrix metalloprotease (MMP) 2; Pr-mulgin 2 and 3 strongly inhibited trypsin and plasma plasmin; and $P r$-mulgin 2 also inhibited $\alpha$-chymotrypsin (Table 1). No inhibitory effects were observed against other proteases such as serine proteases (elastase, kallikrein and pepsin), cysteine protease (cathepsin G), and MMPs (1,3,7,8,9,10,12,13 and 14). These peptides did not block Drosophila $\mathrm{K}^{+}$channels (Shaker) and rat $\mathrm{K}^{+}$channels $\left(\mathrm{K}_{\mathrm{v}} 1.1\right)$. 
Recently, a trypsin inhibitor named PIVL (Table 1) was characterized from the venom of the Tunisian snake Macrovipera lebetina transmediterranea [64]. Besides trypsin inhibitory activity, PIVL also exhibits anti-tumor effect and displays integrin inhibitory activity without being cytotoxic. No inhibitory effect was detected on chymotrypsin.

Transcriptomic approaches are also showing numerous serine PIs in snake venoms. Transcriptome of the venom glands of the Australian elapid snake Drysdalia coronoides revealed that serine protease inhibitors are one of the major components from this venom [126]. The presence of putative Kunitz-type inhibitors was also shown in the venom gland transcriptomes of the elapid snakes Bungarus multicinctus and Naja atra [127], of the viper snake Vipera nikolskii [128], of the Brazilian coral snake Micrurus altirostris [129], and from several Australian elapid snakes [125].

Other classes of PIs in snake venoms comprise the cystatins and the bradykinin-potentiating peptides (BPPs). The cystatins are a family of cysteine protease inhibitors with homology to chicken cystatin/ovocystatin and human cystatin C [130]. To date, few snake venom cystatins have been fully characterized, and some of them were shown to inhibit papain-like cysteine proteases [131-134]. BPPs consist of about 5-14 amino acid residues that specifically block the endothelial metalloprotease angiotensin I-converting enzyme (ACE). The first report of a "bradykinin-potentiating factor (BPF)" in the venom of Bothrops jararaca was in 1965 [135]. These factors were subsequently purified and characterized as peptides responsible for potentiating the activity of bradykinin and inhibition of ACE [136,137]. Among a series of analogs of BPPs studied, one of them was modified to produce captopril, an orally available peptidomimetic that, together with further modified molecules, become widely used for the treatment of hypertension [138]. Although not presented in detail in this review, other BPPs have been identified in snake venoms or venoms glands [139-143].

\subsection{PIs from Scorpion Venoms}

The first report on a protease inhibitor from scorpion venom was made in 1981 by Chhatwal and Habermann [66]. The peptide was purified from the venom of the Indian red scorpion Mesobuthus tamulus and consisted of 77 amino acid residues and 8500 Da (Table 1). It inhibited trypsin and also kallikrein, but had weak or no activity against chymotrypsin, plasmin and thrombin [66]. Its sequence, however, was not revealed.

Posteriorly, Schwartz and collaborators [67] reported for the first time, by means of transcriptomic analysis, the presence of a Kunitz type precursor in scorpions. The mature peptide, named Hg1, from the Mexican scorpion Hadrurus gertschi, was not found in the venom and its activity remained unknown, until it was recently expressed by Escherichia coli BL21(DE3) cells, purified and tested [68]. Together with Hg1, other six recombinant scorpion peptides (LmKTT-1a, LmKTT-1b, LmKTT-1c, BmKTT-1, BmKTT-2 and BmKTT-3) were also characterized as trypsin inhibitors (Table 1), with no activity against chymotrypsin or elastase even at high doses [68]. Among them, recombinant $\mathrm{Hg} 1$ presented the lowest dissociation constant against trypsin, while rBmKTT-3, from Mesobuthus martensii, had the highest [68]. LmKTT-1b, also named SdPI, from Lychas mucronatus, was the first functionally characterized Kunitz-type peptide from scorpion [16]. All these seven recombinant peptides seem to have similar secondary structure to BPTI, as analyzed by circular dichroism spectroscopy [68]. Moreover, some of them are also blockers of potassium channels (Table 2) [68]. 
From the cDNA libraries constructed from the venom glands of three scorpion species, four putative serine protease inhibitors belonging to the Ascaris-type peptides were recently identified: SjAPI (Scorpiops jendeki Ascaris-type protease inhibitor), SjAPI-2 (Scorpiops jendeki Ascaris-type protease inhibitor 2), CtAPI (Chaerilus tricostatus Ascaris-type protease inhibitor), and BmAPI (Buthus martensii Ascaris-type protease inhibitor) [69]. Members of the Ascaris-type peptides' family are characterized by the presence of five disulfide bonds [144]. The recombinant SjAPI (Table 1) inhibited both $\alpha$-chymotrypsin and elastase, with no detectable effect on trypsin. SjAPI is produced as a precursor polypeptide of 94 amino acid residues, which includes a signal peptide of 24 residues, a propeptide of 6 residues, and a 64-residue mature peptide [69].

Besides these serine protease inhibitors, a plasmin inhibitor named discreplasminin was isolated from Tityus discrepans scorpion venom. It has an antifibrinolytic mechanism similar to aprotinin and probably interacts with the active sites of plasmin and tPA, a tissue-type plasminogen activator [145]. Moreover, a putative serpin peptidase inhibitor-like protein (UniProtKB C5J8C1) was identified in the cDNA venom gland library of Opisthacanthus cayaporum. However, it is composed by 176 encoded amino acid residues and lacks the signal peptide region [146].

\subsection{PIs from Spider Venoms}

Yuan and collaborators reported the first superfamily of Kunitz-type toxins from spiders [14]. It is composed by HWTX-XI, the prototype member of this superfamily, and 45 additional putative KTTs, which were found by means of two venom gland cDNA libraries constructions of the two Chinese bird spiders Ornithoctonus huwena and O. haiana (34 and 11 putative KTTs, respectively). HWTX-XI (Table 1) has $6166.23 \mathrm{Da}$ and six cysteine residues. It was isolated from both venom and venom gland extract of $O$. huwena. HWTX-XI inhibits trypsin stoichiometrically in a 1:1 ratio and strongly binds to trypsin, while presenting lower affinity to $\alpha$-chymotrypsin. It had about 30 -fold higher inhibition potential to trypsin compared with BPTI, with a $K_{\mathrm{d}}$ value of $2.3 \times 10^{-10} \mathrm{M}$, while BPTI had a $K_{\mathrm{d}}$ of $6.57 \times 10^{-9} \mathrm{M}$ under the same experimental conditions [14]. Similar to many KTTs, HWTX-XI also inhibits potassium channel currents (Table 2).

After that, a putative serine protease inhibitor was revealed from the cDNA library of Loxosceles intermedia venom gland [147]. This single EST (cluster LIS209) presented high similarity with serine protease inhibitors from mammals, such as Mus musculus (UniProtKB O35684) and Pan troglodytes, and also from Ambliomma americanum tick.

Recently, the first spider Kunitz-type inhibitor with plasmin and elastase inhibitory activity (AvKTI, Table 1) was identified in Araneus ventricosus [70]. However, its coding clone was selected from the expressed sequence tags (ESTs) that were generated from a cDNA library constructed using A. ventricosus whole bodies. Because AvKTI is expressed only in the epidermis, it is suggested that it is a Kunitz-type inhibitor derived from the spider body, but not from venom [70]. Recombinant AvKTI inhibited both trypsin and chymotrypsin, with no detectable inhibitory effects on factor Xa, thrombin or tissue plasminogen activator (tPA). However, it inhibited plasmin and neutrophil elastase [70]. Thus, among the proteases tested, the most prominent inhibitory effect of AvKTI was observed on plasmin, resembling other PIs with antifibrinolytic activity, such as scorpion discreplasminin [145] and snake textilinins [7,122]. In addition, another Kunitz-type inhibitor (AvCI, Table 1) was obtained from 
A. ventricosus in a similar manner to AvKTI [71]. AvCI inhibits chymotrypsin, the microbial serine proteases subtilisin $\mathrm{A}$ and proteinase $\mathrm{K}$, and also the human neutrophil elastase and porcine pancreatic elastase. It was ineffective against trypsin, factor Xa, thrombin, tPA and plasmin [71].

\subsection{PIs from the Skin Secretion of Anurans}

The skin granular glands of Anurans (frogs and toads) produce a remarkably diverse range of bioactive polypeptides [17]. Among them, almost all the serine protease inhibitors from amphibians contain 3-5 conserved disulfide bridges, with few exceptions [85-87], and their biological role is still not clear [87]. Unless otherwise stated, all amphibian PIs described in this section were obtained from their skin secretions.

From the toad Bombina bombina, a 60-residue polypeptide cross-linked by five disulfide bridges was isolated and cloned [72]. Named BSTI, it inhibits both porcine trypsin and human thrombin (Table 1), with no activity against chymotrypsin. Its precursor contains 84 amino acid residues, including a 24-residue signal peptide [72]. Structurally homologous to BSTI, a trypsin inhibitor named BMTI (Table 1) was characterized from the toad Bombina maxima [73]. Its precursor also contains 84 amino acid residues, with a putative signal peptide of 24 residues. Unlike BSTI, BMTI had no inhibitory effect on thrombin. Chymotrypsin, elastase and bacterial subtilisin were also not inhibited at up to $10 \mu \mathrm{M}$ concentration. Also with five disulfide bridges, a weak trypsin inhibitor was isolated from the frog Rana areolata (Table 1) [74].

In addition, two trypsin inhibitor analogs (BOTI and BVTI) were isolated from the toads Bombina orientalis and Bombina variegata (Table 1) [75]. By means of a new non-invasive technique, two cDNA libraries were constructed from the dermal venom of these two species and both precursors were obtained, which contain 84 amino acid residues, including a 24-residue signal peptide. The trypsin inhibitory activity of BOTI and BVTI was not measured [75].

From the toad Bombina microdeladigitora, two serine protease inhibitors structurally homologous to BSTI were identified (BMSI 1 and BMSI 2, Table 1) [76]. BMSI 1 inhibits both trypsin and thrombin. No inhibition of the hydrolysis of substrates by elastase, chymotrypsin and subtilisin were observed with an inhibitor concentration up to $10 \mu \mathrm{M}$.

From Hyla simplex, two serine protease inhibitors were isolated (Table 1) — an alpha-1-antitrypsin-like serpin (hylaserpin-S1) and a wasp venom-like toxin (hylaserpin-S2) [77]. Hylaserpin-S2 precursor is composed by 83 amino acid residues, including a predicted signal peptide of 27 residues. It is structurally related to those amphibian serine protease inhibitors containing five disulfide bridges from Bombina and Rana genera [72-75]. Hylaserpin-S1 is a much longer peptide, with $44 \mathrm{kDa}$, and is encoded by a 415-amino acid residues precursor, with a signal peptide of 23 amino acid residues. Hylaserpin-S1 inhibited both trypsin and chymotrypsin, whereas hylaserpin-S2 only inhibited trypsin, similarly to BSTI [72,77]. Moreover, hylaserpin-S2 had bacteriostatic effect against Gram-positive bacteria Bacillus subtilis, and hylaserpin-S1 displayed direct microorganism-killing abilities against B. subtilis, E. coli, and Candida albicans [77].

Another long protease inhibitor, consisting of a basic single chain glycoprotein with about $22 \mathrm{kDa}$, was isolated from the toad Bufo andrewsi (BATI, Table 1). BATI inhibits trypsin, but displays no inhibitory activity against chymotrypsin, thrombin and elastase [78]. Also from Bufo andrewsi, 
an irreversible serine protease inhibitor (baserpin, Table 1) also consisting of a single chain glycoprotein with $\sim 60 \mathrm{kDa}$ was purified. Baserpin, which possibly belongs to the serpin superfamily, inhibits the catalytic activity of trypsin, chymotrypsin and elastase, with no detectable inhibitory effects on thrombin [79]. Similar to BATI, the peptide KPHTI (Table 1), from the frog Kaloula pulchra hainana, is a single chain glycoprotein with about $23 \mathrm{kDa}$, and also inhibits trypsin, but not chymotrypsin, thrombin, elastase or subtilisin [80]. Only few $N$-terminal residues from BATI, baserpin and KPHTI were sequenced [78-80].

An albumin-like protein with approximately $60 \mathrm{kDa}$ (albumin-1, UniProtKB Q3T479) was isolated and cloned from Bombina maxima skin [148]. Purified from skin homogenate, this protein inhibits trypsin $\left(K_{\mathrm{d}}\right.$ of $1.92 \mathrm{nM}$ ), with no inhibition against thrombin, chymotrypsin, elastase or subtilisin. However, this protein, which shares similar biochemical and immunochemical properties as those of the B. maxima serum albumin, was not detected in the skin secretions [148].

Two peptides analogous to the Kazal family of serine protease inhibitors were obtained from the skin extract of Phyllomedusa sauvagii (PSKP-1 and PSKP-2, Table 1) [81]. Recombinant PSKP-1 inhibited a serum prolyl endopeptidase from blood serum, but was not active against trypsin, chymotrypsin, V8 protease or proteinase K. In addition, PSKP-1 displays bactericidal activity and induces agglutination of red cells and bacteria [81]. Similar to these peptides, two putative protease inhibitors (PI01 and PI02) were obtained from the cDNA library of Phyllomedusa nordestina (Table 1). The third of them (PI03) is shorter and structurally different [82]. A different Kazal-type protein with potent trypsin inhibitory activity (ACKTI, Table 1) was characterized from the frog Agalychnis callidryas [83]. Its precursor contains 78 amino acid residues, including a signal peptide with 26 residues.

A Kunitz-type protease inhibitor (Table 1) was isolated from the skin secretion of the tomato frog Dyscophus guineti [17]. It contains 57 amino acid residues, including six cysteine residues, and inhibits trypsin. In addition, a chymotrypsin inhibitor of Kunitz-type (KSCI, Table 1) was characterized from Kassina senegalensis [84]. Its precursor sequence contains 84 amino acid residues, including a 22-residue putative signal peptide.

From the frog Hyla annectans, a different Kunitz-type inhibitor peptide (anntoxin, Table 1) with additional (although weak) sodium channel activity was characterized [85]. It inhibits tetrodotoxin-sensitive (TTX-S) sodium channel currents elicited from adult rat dorsal root ganglion neurons with an $\mathrm{IC}_{50}$ value of $3.4 \mu \mathrm{M}$, and is also lethal to different potential predators, like insects, snake, birds, and mice. Calcium and potassium currents were few or not inhibited even at concentrations up to $10 \mu \mathrm{M}$. Anntoxin inhibits trypsin and is homologous to KTTs, but contains only two of the three highly conserved disulfide bridges [85].

The first small serine protease inhibitor known to contain only a single disulfide bond characterized from animals was isolated and cloned from the skin secretion of the frog Odorrana grahami [86]. Five different precursors, although highly conserved, encode OGTI. All of them contain 70 amino acid residues including a signal peptide of 22 residues, an acidic spacer peptide with 31 residues and equal mature peptides with 17 residues. OGTI toxin inhibited trypsin (Table 1), but had no inhibitory effects on thrombin, chymotrypsin, elastase, subtilisin, plasmin or furin at concentrations up to $10 \mu \mathrm{M}$ [86]. Similar precursors encoding mature peptides equal to OGTI seem to have been found in the skin secretions of Odorrana andersonii (UniProtKB E3SZL1), Odorrana margaretae (UniProtKB E1AWD0) and Rana schmackeri (UniProtKB D5LXG2). 
Another small peptide with only one disulfide bond (HV-BBI, Table 1) was characterized from the frog Huia versabilis (=Odorrana versabilis) [87]. This Bowman-Birk type protease inhibitor is encoded by a precursor of 62 amino acid residues, including a 22-residue signal peptide, a 22-residue propeptide, and a mature peptide consisting of 18 amino acid residues and a $C$-terminal amidation. The synthetic peptide was found to behave as a competitive reversible inhibitor of trypsin. No chymotrypsin inhibitory activity was observed [87].

\subsection{PIs from Hymenopterans' Venoms}

There are few reports on serine protease inhibitors from the venom of Hymenopterans, such as wasps and bees. Moreover, some of them are putative PIs, obtained by means of transcriptomic tools, and have not been tested yet.

From the venom of the solitary spider wasp Anoplius samariensis, a peptide named As-fr-19 (UniProtKB Q589G4) was purified and cloned [149]. Its precursor encodes a peptide with 75 amino acid residues, containing a signal peptide of 17 residues and a mature toxin of 58 residues. As-fr-19 contains six cysteine residues and presents sequence similarity to some sea anemone and snake toxins, such as the kalicludines from Anemonia sulcata [27] and snake dendrotoxin I and $\mathrm{K}$ and calciludine [108,111]. Thus, As-fr-19 may exert inhibitory effects on serine proteases and on potassium and/or calcium channels [149].

Using random sequencing analysis, novel putative toxins from the venom of the parasitoid wasp Pimpla hypochondriaca have been sequenced [150]. Among the cysteine-rich venom proteins, four of them (cvp1, cvp2, cvp4 and cvp6) presented sequence similarity with protease inhibitors. Both cvp1 and cvp6 contain 10 cysteine residues and are similar to the chymotrypsin inhibitor AMCI 1 from the larval hemolymph of Apis mellifera (UniProtKB P56682). Mature cvp2 shares high sequence similarity to Kunitz-type serine protease inhibitors, and cvp4 consists of a three times repeated six cysteine motif and is similar to pacifastin, a protease inhibitor from locust (UniProtKB Q8WQ22).

A serine protease inhibitor polypeptide named bicolin (Table 1) was characterized from the venom of the wasp Vespa bicolor Fabricius [88]. Its precursor is composed of 77 amino acid residues comprising a 23-residue predicted signal peptide and the 54-residue mature toxin cross-linked by three disulfide bonds. Bicolin is homologous to As-fr-19 and cvp2 and showed inhibitory activity against trypsin and thrombin, but had no effect on elastase and chymotrypsin. Bicolin was found to own anticoagulation function, possibly due to its thrombin-inhibitory activity [88].

From Bombus ignitus bumblebee venom, a Kunitz-type serine protease inhibitor (Bi-KTI, Table 1) with plasmin inhibitory activity was characterized [6]. Its precursor consists of 82 amino acid residues, with a predicted 24-residue signal peptide and a 58-residue mature peptide, including six cysteine residues. It strongly inhibits plasmin, although its inhibitory activity was approximately two-fold weaker than that of aprotinin. Bi-KTI did not inhibit other enzymes from the hemostatic system, such as factor Xa, thrombin, or tPA. These results are similar to those of snake textilinins [7,122]. Bi-KTI, which acts as an antifibrinolytic agent, and Bi-VSP, a Bombus ignitus venom serine protease previously characterized that acts as a fibrin(ogen)olytic agent [151], may act in a cooperative fashion to promote the spread of bee venom under anti-bleeding conditions [6]. 
Similar results were obtained with the Kunitz-type inhibitor Bt-KTI (Table 1), from Bombus terrestris bumblebee venom [89]. Bt-KTI shares high sequence similarity to Bi-KTI and also consists of a 58-amino acid residue mature peptide, including six conserved cysteine residues. Moreover, it displays strong inhibitory activity against plasmin, exhibiting an antifibrinolytic activity, and does not inhibit factor Xa, thrombin or tPA [89].

From a cDNA library constructed using Asiatic honeybee (Apis cerana) whole bodies, a putative chymotrypsin inhibitor (AcCI) with ten conserved disulfide bridges was identified [152]. Based on the RT-PCR done with samples of epidermis, fat body, midgut, and venom gland, the AcCI gene was found to be constitutively expressed in all of these tissues. The recombinant AcCI ( $\mathrm{AcCI}$ ), obtained by a baculovirus/insect cell expression system, inhibited the activity of chymotrypsin $\left(\mathrm{IC}_{50}: 24.71 \mathrm{nM}\right)$, with an inhibitory constant $\left(K_{\mathrm{i}}\right)$ of $11.27 \mathrm{nM}$, and of human neutrophil $\left(\mathrm{IC}_{50}: 38.50 \mathrm{nM}\right)$ and porcine pancreatic $\left(\mathrm{IC}_{50}: 70.21 \mathrm{nM}\right.$ ) elastases, with $K_{\mathrm{i}}$ values of $61.05 \mathrm{nM}$ and $101.89 \mathrm{nM}$, respectively. rAcCI had no inhibitory activity against trypsin, factor Xa, thrombin, tPA, or plasmin. It is worthy to mention that although AcCI precursor codes to a 65-amino acid residue mature peptide, with a predicted molecular mass of $7.2 \mathrm{kDa}$, rAcCI was identified as a $16-\mathrm{kDa}$ protein, which was interpreted by authors as due to the presence of carbohydrate moieties [152].

\section{PIs and Potassium Channel Activity}

It is suggested that the evolution process of Kunitz-type toxins has probably three stages: old functional molecules, bi-functional toxins and new function toxins [14]. Thus, some Kunitz-type protease inhibitors could acquire the neurotoxin function, whereas others would even lose their protease inhibitory role and act on voltage-gated ion channels [14,116]. Potent and specific neurotoxic $\mathrm{K}^{+}$channel blockers with Kunitz-type motif are particularly developed in snakes, while sea anemone, scorpion and spider toxins have developed only the dual-functional KTTs, frequently with weak $\mathrm{K}^{+}$ channel blocking activity. One possible explanation is that the selective pressure would have act in order to keep the dual-functional KTTs with weak $\mathrm{K}^{+}$channel blocking activity in these latter animals, which already have other potent neurotoxins in their venoms/body extracts. By contrast, only $\mathrm{K}^{+}$ channel blockers presenting the Kunitz-type motif were characterized from snake venoms so far [14].

Typical examples of this are the snake dendrotoxins. Although being similar to Kunitz-type protease inhibitors in amino acid sequences and three-dimensional conformation [153], dendrotoxins display few or no serine protease inhibitory activity. By contrast, they are strong blockers of potassium channels (Table 2) [95,110]. Both dendrotoxin (or $\alpha$-dendrotoxin, UniProtKB P00980) from green mamba Dendroaspis angusticeps and toxin I (UniProtKB P00979), from the black mamba Dendroaspis polylepis, block cloned $\mathrm{K}_{\mathrm{v}} 1.1, \mathrm{~K}_{\mathrm{v}} 1.2$ and $\mathrm{K}_{\mathrm{v}} 1.6$ channels in the low nanomolar range $\left(K_{\mathrm{d}}<20 \mathrm{nM}\right)[95,154]$. Toxin K (UniProtKB P00981), also from the black mamba D. polylepis, preferentially blocks $\mathrm{K}_{\mathrm{v}} 1.1$ channels and is active at picomolar concentrations [96,155]. Other subtypes of potassium channels are also blocked by some dendrotoxins, although with lower affinity [95]. The protein $\mathrm{E}$ homologues from green mamba venom are also able to block $\mathrm{K}_{\mathrm{v}} 1.1$ channels expressed in oocytes, although higher concentrations are needed (Table 2) [98]. Named "DaE1" and "DaE2", these polypeptides share 98\% and 95\% identity, respectively, to trypsin inhibitor E from black mamba venom [156]. 
By means of chemical modifications of native dendrotoxins and genetic engineering to produce mutated toxins, the amino acid residues that are essential for their interaction with potassium channels have been identified [95,110]. Lys5 seems to be the major determinant of the binding affinity of $\alpha$-DTX and DTX-I for $\mathrm{K}^{+}$channels (Figure 1) [157,158]. Along with it, the neighbor hydrophobic residue Leu9 is also important for binding to $\mathrm{K}^{+}$channels [159]. Lys19, which is around the "anti-protease" site, caused only a little loss of activity when acetylated in DTX-I [158] or replaced by Ala in $\alpha$-DTX [159].

Besides Lys5, or the equivalent Lys3 in DTX-K, the amino acids at the $\beta$-turn region (residues 24-28 in toxin K, in particular Trp25 and Lys26) are responsible for the potassium channel activity $[160,161]$. In DTX-I, acetylation of Lys29 inactivated the toxin, possibly by producing large structural perturbations [158]. Moreover, although acetylation of Lys28 alone had little effect, the toxin became almost inactive when both Lys28 and Tyr24 were modified [158]. Differently, in $\alpha$-DTX, modification of the Lys triplet 28-30 to Ala-Ala-Gly exhibited only small decreases in biological activity [162]. Seven amino acid residues (Lys3, Tyr4, Lys6, Leu7, Pro8, Arg10 and Lys26) from $\delta$-dendrotoxin were shown to be important for the toxin's interaction with a Shaker channel variant [163].

The heterodimeric snake neurotoxin $\beta$-bungarotoxin inhibits the release of acetylcholine from motor nerve endings [164]. It consists of a $\mathrm{PLA}_{2}$ subunit and a $\mathrm{K}^{+}$channel binding subunit, which is a member of the Kunitz-type protease-inhibitor superfamily, both linked by a disulfide bridge [165]. $\beta$-Bungarotoxin acts on a presynaptic potassium channel and then, with the phospholipase $\mathrm{A}_{2}$ unit activity, blocks neurotransmission, altering the acetylcholine release [166]. $\beta$-Bungarotoxin $(2 \mu \mathrm{M} / \mathrm{L})$ partially blocked fast $\mathrm{K}^{+}$outward current $\left(\mathrm{I}_{\mathrm{K} . \mathrm{F}}\right)$ through the fast $\mathrm{K}^{+}$channels and also $\mathrm{Ca}^{2+}$-dependent $\mathrm{K}^{+}$current $\left(\mathrm{I}_{\mathrm{K}(\mathrm{Ca})}\right)$ through $\mathrm{Ca}^{2+}$-activated $\mathrm{K}^{+}$channel in motor nerve terminals of snake [167]. The mutated B(C55S)-bungarotoxin chain, where Cys55 was replaced by Ser55, at $200 \mathrm{nM}$, blocked the outward $\mathrm{K}^{+}$current through synaptosomal membranes. However, the $\mathrm{B}$ chain is not the only essential subunit for the binding of $\beta$-bungarotoxin to its target given that it has been shown that $\mathrm{Ca}^{2+}$ is required for the binding of $\beta$-bungarotoxin with its receptors [168] and that the $\mathrm{A}$ chain is the $\mathrm{Ca}^{2+}$-binding subunit of the toxin [169].

Some dendrotoxin homologues have been characterized in other venomous animals, such as sea anemones, cone snails, scorpions and spiders (Figure 1 and Table 2), raising the possibility that the protease inhibitor structural framework has been used to create potassium channel blocking activity, being the new active site different from and independent of the old one [14].

Figure 1. Representative alignment of toxins with the Kunitz-type motif from venomous animals. Organisms from which the polypeptides were obtained are indicated by the colored lines at left: blue, sea anemones; grey, snakes; red, scorpions; yellow, spider; green, Anurans; purple, Hymenopterans; black, cone snail. The toxins that present potassium channel blocking activity are indicated by symbols after their names: - $\mathrm{K}^{+}$channel blockers with no protease inhibitory activity or still not tested against proteases; $\diamond$ and $\diamond$, dual-function toxins, where $\bullet$ denotes toxins with stronger potency in $\mathrm{K}^{+}$channels than those indicated by $\diamond$. The other polypeptides, without symbols, are all serine protease inhibitors. The alignment was generated by ClustalW [170] and the 
consensus sequence was colored using Chroma and manual edition [171]. Key residues for $\mathrm{K}^{+}$channel blocking activity are highlighted in red. Key residues for protease inhibition with more specificity to trypsin or chymotrypsin are highlighted in magenta and cyan, respectively. Some of them were suggested to be key residues by sequence similarity with other toxins. The P1 site residues are pointed by an arrow. Capital letters denote amino acids. Lower-case letters denote: b, big; p, polar; h, hydrophobic; a, aromatic. The known conserved disulfide bridges are labeled in black lines. The black dotted line suggests a possible new disulfide bridge in scorpion venom PIs [99]. The numbers within parenthesis mean amino acid residues from the $C$-terminus of the peptides that were not completely shown in this alignment.
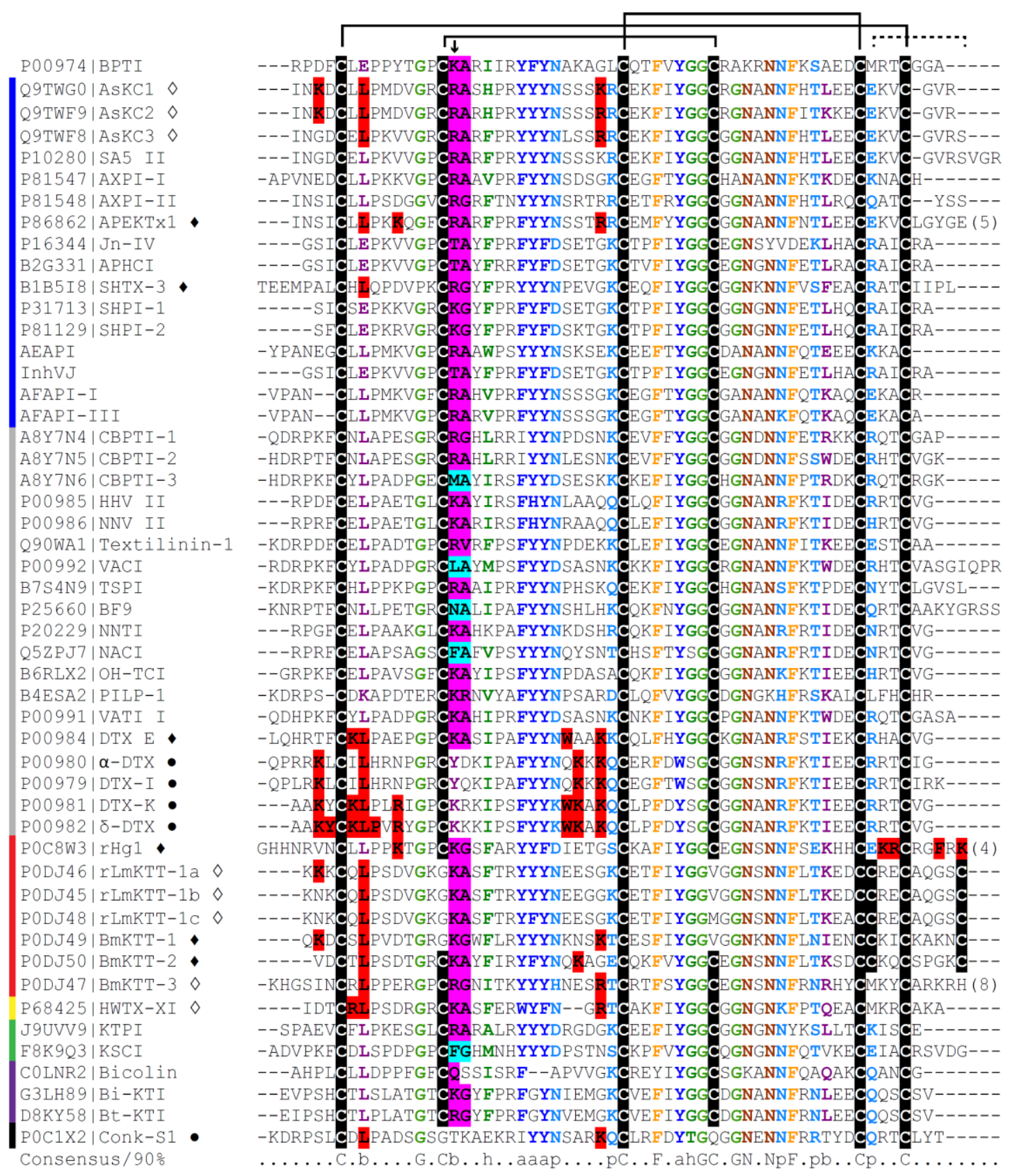

The kalicludines AsKC1, AsKC2 and AsKC3, from the sea anemone Anemonia sulcata, were shown to inhibit the binding of ${ }^{125} \mathrm{I}-\alpha$-dendrotoxin to rat brain membranes in a competitive way, with 
$\mathrm{IC}_{50}$ values of $375 \mathrm{nM}$ for $\mathrm{AsKC} 1$ and $500 \mathrm{nM}$ for AsKC3. AsKC2 had an inhibition constant $K_{\mathrm{i}}$ of $20 \mathrm{nM}$. All these toxins were able to inhibit $\mathrm{K}_{\mathrm{v}} 1.2$ channels expressed in Xenopus oocytes (Table 2) [27]. Similarly, SHTX-3, from the sea anemone Stichodactyla haddoni, inhibited the binding of ${ }^{125} \mathrm{I}$ - $\alpha$-dendrotoxin to rat synaptosomal membranes [40]. Its $\mathrm{IC}_{50}$ value (Table 2) indicated that this toxin is about 110 times less potent than $\alpha$-dendrotoxin, which under the same conditions presented an estimated $\mathrm{IC}_{50}$ value of $5.7 \mathrm{nM}$.

The sea anemone peptide APEKTx1, from A. elegantissima, was subject to a wide screening on 23 ion channels expressed in Xenopus laevis oocytes: 13 cloned voltage-gated $\mathrm{K}^{+}$channels $\left(\mathrm{K}_{\mathrm{v}} 1.1-\mathrm{K}_{\mathrm{v}} 1.6, \mathrm{~K}_{\mathrm{v}} 1.1\right.$ triple mutant, $\mathrm{K}_{\mathrm{v}} 2.1, \mathrm{~K}_{\mathrm{v}} 3.1, \mathrm{~K}_{\mathrm{v}} 4.2, \mathrm{~K}_{\mathrm{v}} 4.3, \mathrm{hERG}$, the insect channel Shaker IR); 2 cloned hyperpolarization-activated cyclic nucleotide-sensitive $\mathrm{Ca}^{2+}$ non-selective channels (HCN1 and $\mathrm{HCN} 2)$ and 8 cloned voltage-gated $\mathrm{Na}^{+}$channels $\left(\mathrm{Na}_{\mathrm{v}} 1.2-\mathrm{Na}_{\mathrm{v}} 1.8\right.$ and the insect channel $\mathrm{DmNa}_{\mathrm{v}} 1$ ) [42]. With exception of $\mathrm{K}_{\mathrm{v}} 1.1$ channel, no significant effects could be observed on the other ion channel isoforms at concentrations up to $1 \mu \mathrm{M}$. The $\mathrm{IC}_{50}$ value for $\mathrm{K}_{\mathrm{v}} 1.1$ channel (Table 2) indicated that APETx 1 inhibits $\mathrm{K}_{\mathrm{v}} 1.1$ channels with the same potency as DTX-I and $\alpha$-DTX. The inhibition of $\mathrm{K}_{\mathrm{v}} 1.1$ channels by this toxin is reversible and not voltage-dependent. APETx1 did not alter channel gating and it presumably acts by blocking the pore in the open state of the $\mathrm{K}_{\mathrm{V}}$ channel. It is suggested that APEKTx1 acts on the channel's extracellular site [42].

It was investigated whether the sensitivity of APEKTx 1 for $K_{v} 1.1$ channels could be affected by mutating 3 amino acid residues (A352P, E353S and $\mathrm{Y} 379 \mathrm{H}$ ) in the dendrotoxin binding site, which is located in the $\mathrm{H} 5$ loop between the transmembrane domains S5 and S6 of $\mathrm{K}_{\mathrm{v}} 1.1 \alpha$-subunit. By doing these mutations, the pore region of this triple mutant closely resembles the one of $K_{v} 1.3$ channels. Even at $100 \mu \mathrm{M}$ concentration, APEKTx1 only induced 53\% current inhibition at the mutated channel, yielding an $\mathrm{IC}_{50}$ value of $10.8 \pm 0.6 \mu \mathrm{M}$, highlighting the crucial interaction of these channel residues with the toxin. The same experiment was performed with DTX-K and it was obtained an $\mathrm{IC}_{50}$ value of $0.51 \pm 0.064 \mu \mathrm{M}$ for wild-type $\mathrm{K}_{\mathrm{v}} 1.1$ channels and $5.28 \pm 0.23 \mu \mathrm{M}$ for the triple mutant channel, which represents a 10 -fold decrease in sensitivity [42].

Despite the high sequence similarity between InhVJ toxin, from the sea anemone $A$. sulcata, and these other sea anemone polypeptides (up to $50 \%$ ), InhVJ did not modified potassium channel currents $\left(\mathrm{K}_{\mathrm{v}} 1.1-\mathrm{K}_{\mathrm{v}} 1.6\right.$, Shaker, $\mathrm{K}_{\mathrm{v}} 2.1, \mathrm{~K}_{\mathrm{v}} 3.1, \mathrm{~K}_{\mathrm{v}} 4.2, \mathrm{~K}_{\mathrm{v}} 4.3$ and cardiac $\mathrm{hERG}$ channel) expressed in Xenopus oocytes in a concentration range of up to $50 \mu \mathrm{M}$ [47]. This inactivity was attributed mainly to the absence of a functional dyad consisting of basic and hydrophobic amino acid residues in the structure of InhVJ. In addition, it was suggested that the small positive charge $(+0.02)$ of InhVJ was apparently not enough to inhibit $\mathrm{K}_{\mathrm{v}}$ channels, since heavily charged polypeptides would interact better with the negative electrostatic potential of the extracellular part of potassium channels [47].

Recombinant conkunitzin-S1, from the cone snail Conus striatus, was shown to inhibit the Shaker potassium channel expressed in Xenopus oocytes (Table 2) [94,105]. Conkunitzin-S1presented high affinity for mutated K427D Shaker- $\Delta 6-46$ channels, with an $\mathrm{IC}_{50}$ value that was in good agreement to that of Conk-S1 obtained from natural source [94].

All seven scorpion protease inhibitors described by Chen and collaborators [68] were tested on $\mathrm{K}_{\mathrm{v}} 1.3$ channels (Table 2). The toxins rLmKTT-1a, rLmKTT-1b and rLmKTT-1c inhibited $\sim 50 \%$ of $\mathrm{K}_{\mathrm{v}} 1.3$ channel currents at $1 \mu \mathrm{M}$ concentration, whereas $\mathrm{rHg} 1, \mathrm{rBmKTT}-1$ and $\mathrm{rBmKTT}-2$ promoted $\sim 60 \%-80 \%$ current inhibition at the same concentration. $\mathrm{rHg} 1$ was also active at $100 \mathrm{nM}$ concentration, 
and rBmKTT-3 had only a weak effect on $\mathrm{K}_{\mathrm{v}} 1.3$ channel currents. $\mathrm{rHg} 1$ was also shown to inhibit $<50 \%$ of the $\mathrm{K}_{\mathrm{v}} 1.1$ and $\mathrm{K}_{\mathrm{v}} 1.2$ channel currents, with little effect on SKCa3 and BKCa channel currents, all at $1 \mu \mathrm{M}$ concentration. These results indicate that $\mathrm{Hg} 1$ is specific for $\mathrm{K}_{\mathrm{v}} 1.3$ channels [68].

Different Hg1 mutants (generated by the alanine-scanning strategy) were tested on $\mathrm{K}_{\mathrm{v}} 1.3$ channels [68], showing no apparent effects of His2, His3, Asn4, Arg5, Leu9 and Lys13 residues on the pharmacological activity of the toxin. Since basic amino acid residues from animal toxins are usually essential for the potassium channel blocking activity $[172,173]$, mutations were performed on the second cluster of basic residues of $\mathrm{Hg} 1$, located at the $C$-terminus of the toxin. Replacement of Lys56, Arg57, Phe61 and Lys63 residues (Figure 1) by alanine significantly reduced the $\mathrm{K}_{\mathrm{v}} 1.3$ blocking activity of mutants by about 94-, 49-, 58- and 74-fold, respectively. Since no molecular conformational changes were observed by circular dichroism analysis between mutants and native peptide, these data indicate that $\mathrm{Hg} 1$ mainly uses its $C$-terminal residues, and not those from its $N$-terminal, to inhibit the $\mathrm{K}_{\mathrm{v}} 1.3$ channel. This is different from the known mechanism of the KTTs such as HWTX-XI and $\delta$-dendrotoxin, which use their $N$-terminal residues to block $\mathrm{K}_{\mathrm{v}} 1.1$ channels $[14,174]$. A structural model of the $\mathrm{Hg} 1-\mathrm{K}_{\mathrm{v}} 1.3$ complex was computationally obtained, supporting the importance of these four $C$-terminal residues of $\mathrm{Hg} 1$ as the channel-interacting surface. Lys56 is the pore-blocking residue; Phe61 contacts residues of the channel A and D chains; and Arg57 and Lys63 mainly contacts residues of the channel D chain [68].

The spider venom toxin HWTX-XI inhibited potassium channels expressed in rat dorsal root ganglion neurons, reducing the amplitude of potassium currents by $41.7 \% \pm 1.8 \%$ at $1 \mu \mathrm{M}$ concentration [14]. Inhibition was voltage- and concentration-dependent, with an $\mathrm{IC}_{50}$ value of $11.6 \mathrm{nM}$. Experiments with $\mathrm{K}^{+}$channel subtypes expressed in X. laevis oocytes showed that HWTX-XI was more active on $\mathrm{K}_{\mathrm{v}} 1.1$ channels $\left(78 \% \pm 7 \%\right.$ inhibition) than on $\mathrm{K}_{\mathrm{v}} 1.2$ and $\mathrm{K}_{\mathrm{v}} 1.3$ $(10 \% \pm 2 \%$ and $28 \% \pm 3 \%$ inhibition, respectively), although a high dose $(5 \mu \mathrm{M})$ was needed (Table 2) [14].

Studies with 18 mutants of HWTX-XI [14], which were constructed through site-directed mutagenesis using HWTX-XI gene as template, showed that the residue Leu6 seems to be essential for the $\mathrm{K}^{+}$channel blocking activity (Figure 1). Its mutation to Ala or Tyr produced about 200-fold reduction in the inhibitory potency. The residues Arg5 and Arg25 seem to have a secondary role in the blocking function, once the mutations R5I and R25A produced about 14 and 4-fold reduction in the potassium channel activity, respectively.

Comparisons between the primary (Figure 1) and tertiary structures of HWTX-XI and DTX-K provided some clues to explain why HWTX-XI is weaker than DTX K for the $\mathrm{K}_{\mathrm{v}}$ channel blocking activity [14]. It was shown that the key residue for channel binding Lys3 in DTX-K is replaced by Asp2 in HWTX-XI, which is negatively charged and has a shorter side chain. Although this amino acid residue may contribute to the smaller blocking activity of HWTX-XI, the mutation D2K in this molecule increased the activity by only about 4-fold. It is possible that the side chain of Lys at the mutant was not at the molecular surface. Another difference between the two compounds is that HWTX-XI does not possess the equivalent residues to Trp25 and Lys26 of DTX-K, which may offer a hydrophobic surface for binding to the turret of $\mathrm{K}_{\mathrm{v}} 1.1$ subunits [14]. 


\section{Molecular Diversity}

As shown in this review, there are several protease inhibitors from venomous animals isolated and characterized from their venoms, body extracts or skin secretion so far. In addition, many of them were identified from transcriptomic approaches and their activity as protease inhibitors is still uncertain.

In sea anemones, most of these polypeptides present the Kunitz-type serine protease inhibitor motif, with three conserved disulfide bridges (with exception of Inhibitor 4, from Rhodactis rhodostoma, which has only two disulfide bridges [31]), and thus are structurally homologous to the bovine pancreatic trypsin inhibitor (BPTI). Only two sea anemone polypeptides were shown to present distinct structural motifs to date - the cysteine inhibitor equistatin, with three thyroglobulin type-1 domains [43], and the non-classical Kazal-type elastase inhibitor (AEI) [30].

The tridimensional structure of BPTI determined by both crystallography and NMR reveals an $\alpha / \beta / \alpha$ structural motif [19-21]. BPTI contains a hydrophobic core and three disulfide bridges $\left(\mathrm{C}_{\mathrm{I}}-\mathrm{C}_{\mathrm{VI}}, \mathrm{C}_{\mathrm{II}}-\mathrm{C}_{\mathrm{IV}}, \mathrm{C}_{\mathrm{III}}-\mathrm{C}_{\mathrm{V}}\right)$, and its structure is characterized by a $3_{10}$-helix at its $N$-terminal (residues 3 to 7 ), a $\beta$-hairpin of residues 18 to 35 , an antiparallel $\beta$-strand involving residue 45 in contact to residue 21 , and an $\alpha$-helix formed by residues $47-56$ at the $C$-terminal [19]. Structural-function relationship analysis of BPTI-enzyme complex has shown that a solvent exposed loop formed by residues 8 to 19 is highly complementary to the enzyme active site (S1 pocket), wherein the P1 residue (Lys15 in BPTI) deeply penetrates to interact with the S1 binding pocket of the protease. Trypsin, which has Asp189 as its S1 site, is particularly suited to interact with the basic side chains of Lys 15 from BPTI [175,176] (Figure 2E).

Regarding the serine superfamily of PIs, three major classes are designated as trypsin-like (positively charged residues Lys/Arg preferred at P1), elastase-like (small hydrophobic residues Ala/Val at P1) or chymotrypsin-like (large hydrophobic residues Phe/Trp/Tyr/Leu/Val at P1) [12,84,177]. The P1 site residues Met, Asn and His for chymotrypsin binding were also reported [50,59,118,177,178]. A catalytic triad of residues (usually Ser, His and Asp) on the enzymes' pocket is responsible for amide bond hydrolysis. Analysis of various mutants of BPTI and other trypsin inhibitors revealed that the interaction inhibitor:trypsin is almost independent of the nature of the basic residue at P1 position, with no significant changes in the association energies with trypsin after the mutation K15R in BPTI [179]. By contrary, inhibition for kallikrein favors Arg over Lys [180,181], while plasmin inhibition is enhanced by Lys at $\mathrm{P} 1$ site [182]. The $\mathrm{P} 1$ ' site of venom trypsin/chymotrypsin inhibitors is occupied by a hydrophobic amino acid residue (Ala, Gly and Phe), being the Ala residue the most commonly used (Figure 1).

The solution structure of ShPI-1, a Kunitz-type protease inhibitor purified from the sea anemone Stoichactis helianthus, was determined by NMR spectroscopy [36]. Despite low sequence similarity between the two polypeptides ( $35 \%$ ), ShPI-1 (Figure $2 \mathrm{~A}$ ) has an almost identical molecular architecture to BPTI, with a $3{ }_{10}$-helix involving residues 1 to 5 , a twisted $\beta$-harpin of residues 16 to 33, a single-residue antiparallel $\beta$ strand of residue 43 and an $\alpha$-helix at the $C$-terminal (residues 45 to 54) [36]. Moreover, the crystallographic structure of ShPI-1 in complex with bovine pancreatic trypsin was revealed (PDB ID: 3M7Q) [39]. The overall structure of this complex is highly similar to the homologous complexes with BTPI (PDB ID: 2FTL and 3OTJ) [183], which is characterized by the lowest dissociation constant known so far for an inhibitor-protease interaction $\left(K_{\mathrm{i}}\right.$ of $\left.6 \times 10^{-14} \mathrm{M}\right)$ [184]. 
Around $40 \%$ of the total interactions at the interface rShPI-1A:trypsin are formed by Lys 13 at P1 position (Figures 1 and 2A), whose side chain interacts with Asp189 at the trypsin catalytic pocket, similarly to BPTI [175]. Additional contributions to the stability of the complex ShPI-1:trypsin are indicated by residues Arg11 (P3 site) and Ile32. The side chain of Arg11 points directly into a pocket on the enzyme surface (S3 site), establishing additional H-bonds at the complex in comparison to BPTI, whose proline residue at this position does not deeply enter the S3 pocket due to its cyclic nature [178,183]. The in silico Arg11Ala mutation in ShPI-1 led to a 10-fold increase in the theoretical $K_{\mathrm{i}}$ value against trypsin.

Figure 2. Tridimensional structures of polypeptides from venomous animals with the Kunitz-type inhibitor motif (A-D) and bovine pancreatic trypsin inhibitor (BPTI): trypsin complex (E). (A) ShPI-1 (PDB code 1SHP) from the sea anemone Stoichactis helianthus; (B) conkunitzin-S1 (PDB code 2CA7) from the cone snail Conus striatus; (C) HWTX-XI (PDB code 2JOT) from the spider Ornithoctonus huwena; (D) anntoxin (PDB code 2KCR) from the frog Hyla annectans; (E) BPTI:trypsin complex (PDB code 3OTJ). The structures are shown as ribbon diagrams, where $\alpha$-helixes are indicated by red color, $\beta$-strands by yellow, $3_{10}$-helix by dark blue; and disordered structure by silver. In detail, Lys residue at P1 position (cyan at A, C and D). In BPTI:trypsin complex, interacting amino acid residues are shown in dark grey for BPTI (Lys15 residue at P1 position) and in orange for trypsin (Asp189 at S1 position). A, C, D and $\mathbf{E}$ were obtained with the software VMD (visual molecular dynamics) [185], whereas B was obtained with the software Discovery Studio 3.5 (Accelrys, Inc., San Diego, CA, USA).
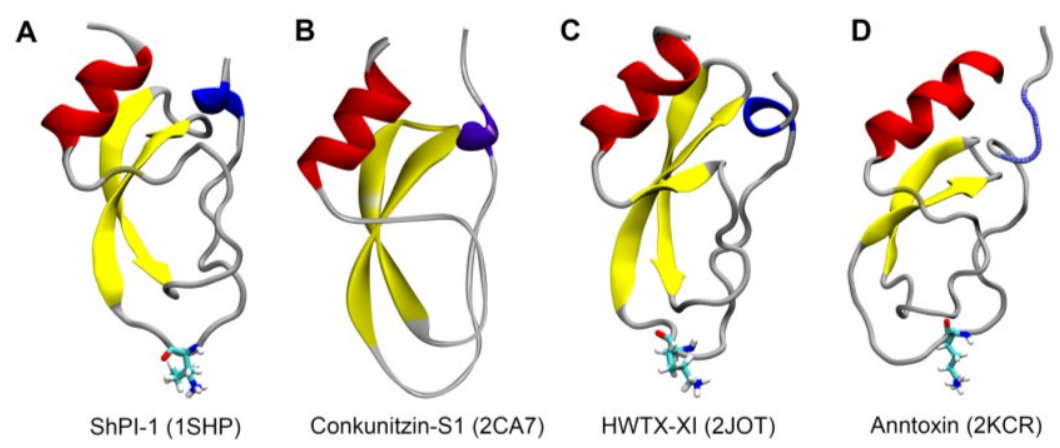

$$
\text { E }
$$

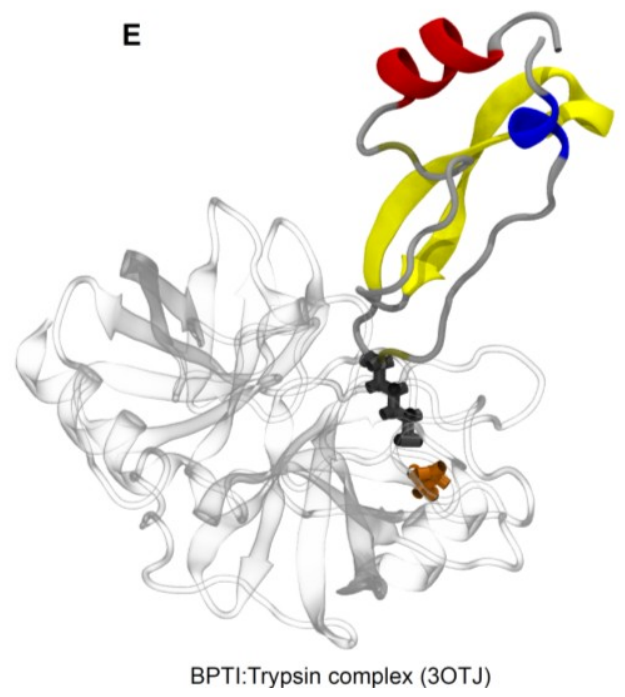


The sea anemone protease inhibitors kalicludines (AsKC1 to AsKC3) and ShPI-2, from Anemonia sulcata and Stoichactis helianthus, respectively, along with some Kunitz-type PIs from snakes, scorpions and spiders (Figure 1) also present Arg residue at the P3 position. Sea anemone kalicludines contain the residues Arg15 and Ala16 at P1 and P1' positions, respectively, which are important for good trypsin binding. However, the presence of Pro19-equivalent to Pro21 in dendrotoxin, which is suggested to cause unfavorable feature for trypsin binding [153]—may explain the weaker inhibitory activities of kalicludines in comparison to BPTI, which has an Ile residue at the equivalent position [27].

The molecular diversity of Kunitz-type inhibitor homologs in Heteractis crispa was examined by using PCR-based cloning techniques, revealing that the H. crispa polypeptides are encoded by a multigene superfamily, which was divided into four distinct groups according to the $N$-terminal amino acid residues (GS-, RG-, GG-, and GN-) [15]. According to the nature of P1 residue, 33 deduced mature GS-polypeptides were categorized into three groups: group I (with Lys at P1 site), group II (Thr at P1), and group III (Arg at P1). Most of transcripts were placed in group I (66.1\%), $24 \%$ generated group II, and $9.9 \%$ was in group III. Phylogenetic analysis suggested that the GS-polypeptide genes, as well as those from other sea anemone Kunitz-type inhibitors, have evolved from a common ancestor. The ancestral polypeptide more likely contains Arg as the P1 residue and Gly in position 38, as these important residues are shared by most of sea anemone Kunitz-type inhibitors (Figure 1) and members of group III [15].

The P1 site is occupied by a Thr residue, instead of Lys/Arg, in the sea anemone polypeptides InhVJ, Jn-IV and APHC1-APHC3 (Figure 1). Because the serine protease inhibitor InhVJ, from the sea anemone Heteractis crispa, is homologous to ShPI-1 (87\% identity), its spatial structure could be model using the structure of ShPI-1 as a template, and the model was used to predict the structure of the complex InhVJ:trypsin [47]. Docking analysis showed a smaller number (three) of H-bond formed by the P1 Thr residue of InhVJ with the trypsin active site in comparison to those of ShPI-1 (five) and of BPTI (seven), which correlate well with the decreasing $K_{\mathrm{i}}$ values of their complexes. Electrostatic interactions and H-bonds of Glu45 at the weak contact site with protease Lys60 and Tyr39 were also important to stabilize the InhVJ:trypsin complex [47]. The conformational stability of InhVJ was analyzed by circular dichroism (CD) spectroscopy [186]. It was shown to be highly stable to changes in temperature and $\mathrm{pH}$. Even after $70{ }^{\circ} \mathrm{C}$, which is the point of the thermal conformational transition of the polypeptide, InhVJ still retained $80 \%$ of the inhibitory activity. Significant changes were observed on the level of tertiary structure of the molecule in the $\mathrm{pH}$ range 11.0-13.0, which may be explained by the ionization of tyrosine residues. InhVJ is conformationally stable at a low $\mathrm{pH}$ value (2.0). Quenching experiments showed that two tyrosine residues are completely accessible for the quencher, whereas the third residue is partially accessible [186].

From cone snail, only few PIs have been studied. Although sharing similar size and tridimensional structure to the Kunitz-type inhibitors, conkunitzin-S1 (Figure 2B) has only two disulfide bridges [105]. The solution structure of conkunitzin-S1 consists of a $33_{10}$-helix of residues 6-8, a contorted $\beta$-hairpin of residues $20-36$, and an $\alpha$-helix in the $C$-terminus (residues $50-56$ ). The $\mathrm{C}_{\mathrm{I}}-\mathrm{C}_{\mathrm{IV}}$ pair connects the two helices, and the $C$-terminal helix is connected to the $\beta$-sheet by the disulfide bridge between $\mathrm{C}_{\mathrm{II}}$ and $\mathrm{C}_{\mathrm{III}}$ [187]. To evaluate the importance of the third disulfide bond to the $\mathrm{K}^{+}$-channel blocker activity, a double cysteine mutant $\left(\right.$Conk-S1 $\left.{ }^{\mathrm{CC}}\right)$ with the additional cysteine bridge 
between the positions 16 and 40 was constructed. Interestingly, wild type and mutant Conk-S1 displayed the same inhibitory activity on Shaker channels [105]. Most of the $\mathrm{K}^{+}$-channel blockers from venomous animals have conserved residues, which are responsible for block of the ion conduction pore and promote a high affinity binding within the $\mathrm{K}^{+}$channel pore vestibule, such as a lysine residue and an aromatic residue at $6.6 \pm 1.0 \AA$ from the $\alpha$ carbon of that lysine, respectively, a motif termed the "functional dyad" [188]. However, different interaction mechanisms have been described, among them, the "basic ring" (four or five non-identical basic residues that might stabilize the interaction with the channels) [189]. In the crystal structure of conkunitzin-S1, positive electrostatic potential is concentrated on one side of the molecule and there is apparently no dyad-like lysine-hydrophobic pair, suggesting that conkunitzin-S1 could interact with $\mathrm{K}^{+}$-channels through its arrangement of positively charged residues.

The scorpion mature peptide rLmKTT-1b (SdPI), from Lychas mucronatus, presents sequence similarity with Kunitz-type inhibitors. However, different from the typical Kunitz-type motif, rLmKTT-1b — along with the scorpion toxins rLmKTT-1a, rLmKTT-1c, and rBmKTT-1 [68] — possess a unique cysteine framework, where the normal $\mathrm{C}_{\mathrm{II}}-\mathrm{C}_{\mathrm{IV}}$ disulfide bridge is absent, such as conkunitizin-S1, but two additional cysteine residues at the $C$-terminus of the mature peptide might generate a new disulfide bridge. As a result, a distinct disulfide assignment may be generated (Figure 1) [16]. Also from scorpion venom PIs, recombinant BmKTT-2 was found to form four disulfide bridges (Table 1 and Figure 1), which is different from all known Kunitz-type animal toxins [68]. AvCI, from the spider Araneus ventricosus (Table 1) also presents the Kunitz-type motif and four disulfide bridges, and although a protease inhibitory activity was observed, this toxin was suggested to derive from the spider whole body, but not from venom [71].

These propositions were recently revealed with the solution structure of rLmKTT-1a [99]. NMR experiments of rLmKTT-1a showed a typical Kunitz-type fold, characterized by a $N$-terminal helix from Lys2 to Cys4, a double-stranded anti-parallel $\beta$-sheets from Phe17 to Asn23 and Lys28 to Tyr34, and a $C$-terminal helix from Asp49 to Ala55, where the disulfide link between Cys51 and Cys59 is presented. Although the sequence similarity is low between LmKTT-1a and classical Kunitz-type toxins, its structure resembles the fold of other inhibitors, such as conkunitzin-S1, dendrotoxin, HWTX-XI, and APEKTx1, suggesting that, despite of molecular diversity, these Kunitz-type peptides hold a structural conservation [99]. The mutant LmKTT-1a-C51A/C59A, with the same disulfide bridge pattern as those of cone snail conkunitzin-S1, and preserving a secondary structure similar to LmKTT-1a, presented a 5-fold lower trypsin inhibitory activity than the native LmKTT-1a, but the same $\mathrm{K}_{\mathrm{v}} 1.3$ channel blocking activity.

The LmKTT-1a gene structure contains two introns in the mature peptide and differs from the genomic organization of the four families of scorpion KTxs, $\alpha-, \beta-, \gamma-$, and $\kappa-$ KTxs. Considering the structural, and functional features, and the genomic organization of scorpion Kunitz-type toxins, it has been proposed a new KTx subfamily to classify these scorpion peptides, the $\delta$-KTx, where the seven members would be divided in three groups based on the disulfide bridge patterns [99].

Molecular dynamics simulation with a proposed rLmKTT-1b:trypsin complex model [16], based on the BPTI interaction with trypsin, showed the active site formed by Lys12, Gly13, Lys14 and Ala15 (Figure 1) inside the S1 pocket of trypsin. In the proximity of the active site there were also strong polar and nonpolar interactions among residues. Peptide Phe17 may also contribute to enhancing the 
rLmKTT-1b:trypsin interaction. The side chain of Lys14, the P1 residue of rLmKTT-1b, protrudes inside the S1 pocket and forms hydrogen bonds with trypsin residues Asp176 and Ser192. Therefore, it is suggested that besides its new disulfide bridge connection, rLmKTT-1b likely interacts with trypsin in a similar way to other Kunitz-type toxins [16].

Recently, four putative serine PIs belonging to the Ascaris-type peptides were identified in scorpion cDNA libraries [69]. Members of the Ascaris-type peptides' family are characterized by four short $\beta$-strands arranged in two approximately perpendicular $\beta$-sheets and stabilized by five disulfide bridges [144].

The NMR solution structure of spider Kunitz-type toxin HWTX-XI (Figure 2C) [14] resembles the structures of BPTI and DTX-K $[19,190]$. In the $N$-terminal of HWTX-XI, from Thr3 to Arg5, there is a $3{ }_{10}$-helix, and in the $C$-terminal, there is an $\alpha$-helix from Gln45 to Cys52 and a triple-stranded anti-parallel $\beta$-sheet formed by Glu18-Asn23, Thr26-Ile31 and Lys41-Phe42. The two helixes are connected by the disulfide bond Cys4-Cys52, and the $\alpha$-helix is connected to the $\beta$-sheet by the disulfide bond Cys27-Cys48.

The studies with 18 mutants of HWTX-XI [14] showed that Lys 14 is the main amino acid residue responsible for the trypsin inhibition function, since the mutation $\mathrm{K} 14 \mathrm{~N}$ reduced in approximately $10^{5}$-fold the inhibitory potency and K14A presented no trypsin binding activity at all. Thus, HWTX-XI counts with the presence of two separate and functionally independent sites-one for serine protease inhibition and another for potassium channel blockage (Figure 1), as discussed in the previous section.

By comparing the primary and tertiary structures of HWTX-XI and BPTI, the authors suggest some possible reasons for making HWTX-XI a stronger trypsin inhibitor than BPTI [14]. First, the replacement of Arg21 in BPTI by the smaller and non-charged residue Ser16 in HWTX-XI (Figure 1) increases the interaction of Lys14 with the negatively charged residue Asp189 at the bottom of the S1 pocket of trypsin. Second, the Phe17 of HWTX-XI has a larger side chain (phenyl group) than Ile22 of BPTI, and this may lead to a broader hydrophobic surface to interact with the hydrophobic pocket formed by Phe41 and Lys60 of trypsin. Third, the amino groups of the long hydrophobic side chain of Arg12 of HWTX-XI fit perfectly the positive pocket formed by the hydroxyls of Lys145, Ser146 and Gly148 of trypsin. These interactions may be strengthened by the potential hydrogen bonds between them [14].

As shown, most of snake venom serine protease inhibitors characterized to date also belong to the Kunitz-type motif, although some of them do not present inhibitory activity due to the absence of the key residues at P3-P3' (Figure 1).

Among the known protease inhibitors from venomous animals, PIs from Anurans display the major variety in structure length and number of cysteine residues. At least six different classes can be distinguished: long PIs, consisting of a basic single chain glycoprotein varying from 22 to $60 \mathrm{kDa}$; inhibitors with 56-61 amino acid residues and five disulfide bridges that, similar to scorpion SjAPI, are also members of the Ascaris-type peptides' family; Kazal-type serine protease inhibitors varying from 52 to 78 amino acid residues and containing three disulfide bridges; Kunitz-type inhibitors also with three disulfide bridges and 57-62 residues long; long-chain inhibitors with 60 residues and only two disulfide bridges; and the two smallest protease inhibitors from venomous animals, with 17-18 amino acid residues and a single disulfide bridge. 
The mature OGTI, from the frog Odorrana grahami, is one of the smallest protease inhibitors ever found (17 amino acid residues) and contains a six-residue loop cross-linked by one disulfide bridge [86]. Circular dichroism spectroscopy analysis indicated that its conformational distribution is essentially random (94.8\%). The importance of Lys13 to the inhibitory activity was confirmed by the mutation K13A, being the mutated peptide not active against trypsin [86].

The Bowman-Birk type trypsin inhibitor HV-BBI, from the frog Huia versabilis, is also one of the smallest PIs characterized from animals to date [87]. This 18-amino acid residue trypsin inhibitor contains a disulfide loop between Cys5 and Cys15. Substitution of Lys8 at the presumed P1 position in the conserved canonical BBI motif, -TKSIPP-, by Arg resulted in 3-fold decrease in trypsin inhibitory activity $\left(K_{\mathrm{i}}\right.$ of $\sim 57 \mathrm{nM}$ ), whereas replacement by the aromatic residue Phe resulted in complete ineffectiveness. Both the Lys-P1 and Arg-P1 variants had no inhibitory activity against chymotrypsin even at a concentration of $100 \mu \mathrm{M}$. In contrast, the Phe-P1 variant presented a modest chymotrypsin inhibitory activity ( $K_{\mathrm{i}}$ of $\sim 389 \mathrm{nM}$ ). Thus, the Lys residue that occupies the P1 position seems to be optimal for potency of action against trypsin [87].

The amphibian peptide anntoxin, from Hyla annectans, is similar to conkunitzin-S1, having the same four cysteine framework and spacing [85]. The NMR structure of the recombinant peptide (Figure 2D), which presented protease inhibitory activity equal to the native peptide, was also similar to those of conkunitzin-S1 [105]. Its structure consists of a twisted $\beta$-hairpin (Thr20-Phe34), an $\alpha$-helix (Leu49-Ala59), and a short $3{ }_{10}$-helix (Tyr4-Cys6) in the $N$-terminus. Their two disulfide bridges are formed by Cys6-Cys56 and Cys31-Cys52. In anntoxin, the conserved trypsin inhibitor domain and conserved interactive sites were found to be the residues ${ }^{14} \mathrm{KGSGST}^{20}$ [85].

Two other Kunitz-type inhibitors characterized from Anurans, KTPI (Kunitz-type protease inhibitor) and KSCI, were isolated from Dyscophus guineti and Kassina senegalensis, respectively [17,84], and their P1 residues (Figure 1) are in complete agreement with their trypsin (Arg16 in KTPI) and chymotrypsin (Phe17 in KSCI) inhibitory activities.

Among the few protease inhibitors functionally characterized from wasp and bees until now, three of them (bicolin, Bi-KTI and Bt-KTI) share the three conserved disulfide bridges of Kunitz/BPTI-type inhibitors (Figure 1). Besides having an unusual P1 residue (Gln15), bicolin, from the venom of the wasp Vespa bicolor, still shows trypsin and thrombin inhibitory activity [88].

\section{Therapeutic Potential}

Besides being one of the most studied small globular proteins used as tool for protein 3D structure, protein/protein interaction, and molecular recognition studies, the clinical use of BPTI has been advised in cardiac surgery and orthotopic liver transplantation. BPTI has a very high specificity for plasmin, and exerts a significant reduction in hemorrhagic complications, blood-transfusion requirements, and the inflammatory status associated to extra-corporeal circulation [191,192]. Indeed, patients treated with BPTI submitted to repeated cardiac surgery, valve replacement and coronary-artery bypass grafting, presented up to 80 percent less blood loss and up to 60 percent lower transfusion requirements than control groups $[193,194]$. The potential use of textilin-1, a serine protease inhibitor isolated from snake venom, is proposed to reduce blood loss during cardiopulmonary surgery [7,122,195]. 
As broadly known and emphasized in the present review, proteases are essential for most physiological processes and, because of that, protease inhibitors have a wide therapeutic potential on cancer and on CNS, cardiovascular, inflammatory and neurodegenerative diseases, including Alzheimer's disease (reviewed in [11]), as well as on viral and parasitic infections associated to overexpressed or unregulated enzyme activity. More than 50 human diseases have been associated to specific mutations in protease genes [196].

Cysteine protease inhibitors have been proposed as antimalarial drugs, because of the critical role for these proteases in hemoglobin hydrolysis at the trophozoite stage of malaria parasite [197]. These proteases also take part in many human physiological pathways such as antigen processing and prohormone activation, as in some diseases including arthritis, Alzheimer's disease, and cancer-cell invasion, reinforcing the importance of finding new cysteine protease inhibitors.

According to practice guidelines published by the American Association for the Study of Liver Diseases (AASLD) in 2011, the best treatment for genotype 1 chronic hepatitis C virus (HCV) infection is a triple therapy that consists of ribavirin and pegylated interferon- $\alpha$ together with a serine protease inhibitor (telaprevir or boceprevir) [198]. In the Acquired Immunodeficiency Syndrome (AIDS), the HIV protease has become an important therapeutic target leading to the development of several protease inhibitors [199,200], and their use as therapeutic drugs has been associated with a drastic reduction in AIDS morbidity and mortality, although the benefits have been compromised by viral mutation and drug-resistance [201].

\section{Conclusions}

Several protease inhibitors have been isolated from venomous animals, mainly sea anemones, snakes and Anurans. Nevertheless, the characterization of PIs from scorpions, spiders and Hymenopterans has attracted increasing interest from the scientific community, whereas those from cone snails remain less studied. Among the serine protease inhibitors, these polypeptides usually have distinct specificity for different proteases, such as trypsin, chymotrypsin, elastase, plasmin, and others. Because most of toxins from venomous animals are characterized as Kunitz-type serine protease inhibitors and present similar tridimensional structural motifs, their specificity towards serine proteases is mainly associated with P1 amino acid. However, besides the amino acid residues surrounding the reactive site, the residues present in the weak contact loop are also important for the different interactions with various serine proteases.

In addition to the protease inhibitory activity, some of these polypeptides are also blockers of potassium channels, being the site of interaction with these channels different from and independent of that for the protease binding. Evolutionary features suggest that new potassium channel blockers or dual-function neurotoxins have been originated from ancient molecules.

Because of the increasing diversity of known Kunitz-type polypeptides, primary sequence comparisons, along with studies comprising site-directed mutagenesis and conformational analysis, could help better understand which amino acid residues are essential for protease inhibition and also for the dual-function. By analyzing the sequences of BmKTT-1, BmKTT-2 and BmKTT-3 (Figure 1), for example, it is possible to propose that the higher potency of BmKTT-1 on $\mathrm{K}_{\mathrm{v}} 1.3$ channels in relation to these other toxins is because only BmKTT-1 possesses the dyad residues Lys2 and Leu5 
equivalent to those in dendrotoxins. Conversely, LmKTT-1a also possesses these dyad residues, but displays little blocking activity. One possible explanation could be the lack of the second cluster of key residues in the equivalent $\beta$-turn region of dendrotoxins. The sea anemone toxin APEKTx1, in turn, is a potent blocker of $\mathrm{K}_{\mathrm{v}} 1.1$ channels, and although not containing the corresponding Lys5 and Leu9 residues of $\alpha$-DTX and DTX-I, it contains the residues Leu 7 and Lys10, and also the second cluster of key residues. These two regions could be responsible for the higher potassium channel activity in relation to SHTX-3, which is a weak channel blocker. However, the sea anemone kalicludines, which present most of the key residues for $\mathrm{K}^{+}$channel blocking activity, are weak inhibitors of $\mathrm{K}_{\mathrm{v}} 1.2$ channels. Thus, it would be interesting to test them on different subtypes of potassium channels, such as $\mathrm{K}_{\mathrm{v}} 1.1$ and $\mathrm{K}_{\mathrm{v}} 1.3$.

This sort of analysis could lead to the design of more potent protease inhibitors and dual-function polypeptides, and also to their strategically minimization in size, fashioning enhanced and low-priced drugs for diverse therapeutic and biotechnological applications. Moreover, comparative analysis could lead to a global evolutionary model that comprises all these PIs, which are undoubtedly provided with important physiological functions in the source organisms.

\section{Acknowledgments}

The authors are grateful to Solange Rego, from Laboratório de Toxinologia, Universidade de Brasília, for helping with the figure with tridimensional structures. Financial support: CNPq (306524/2012-0 and 564223/2010-7), FAPDF (Rede Pró-Centro-Oeste INOVATOXIN). C.B.F.M. received scholarship from $\mathrm{CNPq}$.

\section{Conflict of Interest}

The authors declare no conflict of interest.

\section{References}

1. Di Cera, E. Serine proteases. IUBMB Life 2009, 61, 510-515.

2. Lingaraju, M.H.; Gowda, L.R. A Kunitz trypsin inhibitor of Entada scandens seeds: Another member with single disulfide bridge. Biochim. Biophys. Acta 2008, 1784, 850-855.

3. Puente, X.S.; Sanchez, L.M.; Gutierrez-Fernandez, A.; Velasco, G.; Lopez-Otin, C. A genomic view of the complexity of mammalian proteolytic systems. Biochem. Soc. Trans. 2005, 33, 331-334.

4. López-Otín, C.; Overall, C.M. Protease degradomics: A new challenge for proteomics. Nat. Rev. Mol. Cell Biol. 2002, 3, 509-519.

5. Oliva, M.L.; Souza-Pinto, J.C.; Batista, I.F.; Araujo, M.S.; Silveira, V.F.; Auerswald, E.A.; Mentele, R.; Eckerskorn, C.; Sampaio, M.U.; Sampaio, C.A. Leucaena leucocephala serine proteinase inhibitor: Primary structure and action on blood coagulation, kinin release and rat paw edema. Biochim. Biophys. Acta 2000, 1477, 64-74. 
6. Choo, Y.M.; Lee, K.S.; Yoon, H.J.; Qiu, Y.; Wan, H.; Sohn, M.R.; Sohn, H.D.; Jin, B.R. Antifibrinolytic role of a bee venom serine protease inhibitor that acts as a plasmin inhibitor. PLoS One 2012, 7, e32269.

7. Masci, P.P.; Whitaker, A.N.; Sparrow, L.G.; de Jersey, J.; Winzor, D.J.; Watters, D.J.; Lavin, M.F.; Gaffney, P.J. Textilinins from Pseudonaja textilis textilis. Characterization of two plasmin inhibitors that reduce bleeding in an animal model. Blood Coagul. Fibrinolysis 2000, 11, 385-393.

8. Salvador, L.A.; Taori, K.; Biggs, J.S.; Jakoncic, J.; Ostrov, D.A.; Paul, V.J.; Luesch, H. Potent elastase inhibitors from cyanobacteria: Structural basis and mechanisms mediating cytoprotective and anti-inflammatory effects in bronchial epithelial cells. J. Med. Chem. 2013, 56, 1276-1290.

9. Kennedy, A.R. Chemopreventive agents: Protease inhibitors. Pharmcol. Ther. 1998, 78, 167-209.

10. Turk, B. Targeting proteases: Successes, failures and future prospects. Nat. Rev. Drug Discov. 2006, 5, 785-799.

11. Abbenante, G.; Fairlie, D.P. Protease inhibitors in the clinic. Med. Chem. 2005, 1, 71-104.

12. Hedstrom, L. Serine protease mechanism and specificity. Chem. Rev. 2002, 102, 4501-4524.

13. Krowarsch, D.; Cierpicki, T.; Jelen, F.; Otlewski, J. Canonical protein inhibitors of serine proteases. Cell Mol. Life Sci. 2003, 60, 2427-2444.

14. Yuan, C.H.; He, Q.Y.; Peng, K.; Diao, J.B.; Jiang, L.P.; Tang, X.; Liang, S.P. Discovery of a distinct superfamily of Kunitz-type toxin (KTT) from tarantulas. PLoS One 2008, 3, e3414.

15. Isaeva, M.P.; Chausova, V.E.; Zelepuga, E.A.; Guzev, K.V.; Tabakmakher, V.M.; Monastyrnaya, M.M.; Kozlovskaya, E.P. A new multigene superfamily of Kunitz-type protease inhibitors from sea anemone Heteractis crispa. Peptides 2012, 34, 88-97.

16. Zhao, R.; Dai, H.; Qiu, S.; Li, T.; He, Y.; Ma, Y.; Chen, Z.; Wu, Y.; Li, W.; Cao, Z. SdPI, the first functionally characterized Kunitz-type trypsin inhibitor from scorpion venom. PLoS One 2011, 6, e27548.

17. Conlon, J.M.; Kim, J.B. A protease inhibitor of the Kunitz family from skin secretions of the tomato frog, Dyscophus guineti (Microhylidae). Biochem. Biophys. Res. Commun. 2000, 279, 961-964.

18. Schechter, I.; Berger, A. On the size of the active site in proteases. I. Papain. Biochem. Biophys. Res. Commun. 1967, 27, 157-162.

19. Berndt, K.D.; Guntert, P.; Orbons, L.P.; Wuthrich, K. Determination of a high-quality nuclear magnetic resonance solution structure of the bovine pancreatic trypsin inhibitor and comparison with three crystal structures. J. Mol. Biol. 1992, 227, 757-775.

20. Wagner, G.; Braun, W.; Havel, T.F.; Schaumann, T.; Go, N.; Wuthrich, K. Protein structures in solution by nuclear magnetic resonance and distance geometry. The polypeptide fold of the basic pancreatic trypsin inhibitor determined using two different algorithms, DISGEO and DISMAN. J. Mol. Biol. 1987, 196, 611-639.

21. Deisenhofer, J.; Steigemann, W. Crystallographic refinement of the structure of bovine pancreatic trypsin inhibitor at 1.5 A resolution. Acta Cryst. 1975, 31, 238-250. 
22. Fritz, H.; Brey, B.; Beress, L. Polyvalent isoinhibitors for trypsin, chymotrypsin, plasmin and kallikreins of sea anemones (Anemonia sulcata), isolation, inhibitory behavior and amino acid composition. Hoppe Seyler Z. Physiol. Chem. 1972, 353, 19-30.

23. Wunderer, G.; Beress, L.; Machleidt, W.; Fritz, H. Broad-specificity inhibitors from sea anemones. Methods Enzymol..1976, 45, 881-888.

24. Minagawa, S.; Sugiyama, M.; Ishida, M.; Nagashima, Y.; Shiomi, K. Kunitz-type protease inhibitors from acrorhagi of three species of sea anemones. Comp. Biochem. Physiol. B Biochem. Mol. Biol. 2008, 150, 240-245.

25. Lenarcic, B.; Ritonja, A.; Strukelj, B.; Turk, B.; Turk, V. Equistatin, a new inhibitor of cysteine proteinases from Actinia equina, is structurally related to thyroglobulin type-1 domain. J. Biol. Chem. 1997, 272, 13899-13903.

26. Ishida, M.; Minagawa, S.; Miyauchi, K.; Shimakura, K.; Nagashima, Y.; Shiomi, K. Amino acid sequences of Kunitz-type protease inhibitors from the sea anemone Actinia equina. Fish. Sci. 1997, 63, 794-798.

27. Schweitz, H.; Bruhn, T.; Guillemare, E.; Moinier, D.; Lancelin, J.M.; Beress, L.; Lazdunski, M. Kalicludines and kaliseptine. Two different classes of sea anemone toxins for voltage sensitive $\mathrm{K}^{+}$channels. J. Biol. Chem. 1995, 270, 25121-25126.

28. Tschesche, H.; Kolkenbrock, H.; Bode, W. The covalent structure of the elastase inhibitor from Anemonia sulcata -A “non-classical” Kazal-type protein. Biol. Chem. Hoppe Seyler 1987, 368, 1297-1304.

29. Wunderer, G.; Machleidt, W.; Fritz, H. The broad-specificity proteinase inhibitor 5 II from the sea anemone Anemonia sulcata. Methods Enzymol. 1981, 88, 816-820.

30. Hemmi, H.; Kumazaki, T.; Yoshizawa-Kumagaye, K.; Nishiuchi, Y.; Yoshida, T.; Ohkubo, T.; Kobayashi, Y. Structural and functional study of an Anemonia elastase inhibitor, a "nonclassical" Kazal-type inhibitor from Anemonia sulcata. Biochemistry 2005, 44, 9626-9636.

31. Mebs, D.; Liebrich, M.; Reul, A.; Samejima, Y. Hemolysins and proteinase inhibitors from sea anemones of the Gulf of Aqaba. Toxicon 1983, 21, 257-264.

32. Sokotun, I.N.; Il'ina, A.P.; Monastyrnaya, M.M.; Leychenko, E.V.; Es'kov, A.A.; Anastuk, S.D.; Kozlovskaya, E.P. Proteinase inhibitors from the tropical sea anemone Radianthus macrodactylus: Isolation and characteristic. Biochemistry. Biokhimiia 2007, 72, 301-306.

33. Zykova, T.A.; Vinokurov, L.M.; Markova, L.F.; Kozlovskaya, E.P.; Elyakov, G.B. Amino acid sequence of trypsin inhibitor IV from Radianthus macrodactylus. Bioorg. Khim. 1985, 11, 293-301.

34. Andreev, Y.A.; Kozlov, S.A.; Koshelev, S.G.; Ivanova, E.A.; Monastyrnaya, M.M.; Kozlovskaya, E.P.; Grishin, E.V. Analgesic compound from sea anemone Heteractis crispa is the first polypeptide inhibitor of vanilloid receptor 1 (TRPV1). J. Biol. Chem. 2008, 283, 23914-23921.

35. Mebs, D.; Gebauer, E. Isolation of proteinase inhibitory, toxic and hemolytic polypeptides from a sea anemone, Stoichactis sp. Toxicon 1980, 18, 97-106. 
36. Antuch, W.; Berndt, K.D.; Chavez, M.A.; Delfin, J.; Wuthrich, K. The NMR solution structure of a Kunitz-type proteinase inhibitor from the sea anemone Stichodactyla helianthus. Eur. J. Biochem. 1993, 212, 675-684.

37. Delfín, J.; Martínez, I.; Antuch, W.; Morera, V.; González, Y.; Rodríguez, R.; Márquez, M.; Saroyán, A.; Larionova, N.; Díaz, J.; Padrón, G.; Chávez, M. Purification, characterization and immobilization of proteinase inhibitors from Stichodactyla helianthus. Toxicon 1996, 34, 1367-1376.

38. Díaz, J.; Morera, V.; Delfin, J.; Huerta, V.; Lima, G.; Rodríguez de la Vega, M.; García, B.; Padrón, G.; Assfalg-Machleidt, I.; Machleidt, W.; Chávez, M. Purification and partial characterization of a novel proteinase inhibitor from the sea anemone Stichodactyla helianthus. Toxicon 1998, 36, 1275-1276.

39. García-Fernández, R.; Pons, T.; Perbandt, M.; Valiente, P.A.; Talavera, A.; González-González, Y.; Rehders, D.; Chávez, M.A.; Betzel, C.; Redecke, L. Structural insights into serine protease inhibition by a marine invertebrate BPTI Kunitz-type inhibitor. J. Struct. Biol. 2012, 180, 271-279.

40. Honma, T.; Kawahata, S.; Ishida, M.; Nagai, H.; Nagashima, Y.; Shiomi, K. Novel peptide toxins from the sea anemone Stichodactyla haddoni. Peptides 2008, 29, 536-544.

41. Minagawa, S.; Ishida, M.; Shimakura, K.; Nagashima, Y.; Shiomi, K. Isolation and amino acid sequences of two Kunitz-type protease inhibitors from the sea anemone Anthopleura aff. xanthogrammica. Comp. Biochem. Physiol. B Biochem. Mol. Biol. 1997, 118, 381-386.

42. Peigneur, S.; Billen, B.; Derua, R.; Waelkens, E.; Debaveye, S.; Beress, L.; Tytgat, J. A bifunctional sea anemone peptide with Kunitz type protease and potassium channel inhibiting properties. Biochem. Pharmacol. 2011, 82, 81-90.

43. Galesa, K.; Strukelj, B.; Bavec, S.; Turk, V.; Lenarcic, B. Cloning and expression of functional equistatin. Biol. Chem. 2000, 381, 85-88.

44. Kolkenbrock, H.; Tschesche, H. A new inhibitor of elastase from the sea anemone (Anemonia sulcata). Biol. Chem. Hoppe Seyler 1987, 368, 93-99.

45. Sokotun, I.N.; Leichenko, E.V.; Vakorina, T.I.; Es'kov, A.A.; Il'ina, A.P.; Monastyrnaia, M.M.; Kozlovskaia, E.P. A serine protease inhibitor from the anemone Radianthus macrodactylus: Isolation and physicochemical characteristics (in Russian). Bioorg. Khim. 2007, 33, 448-455.

46. Sokotun, I.N.; Gnedenko, O.V.; Leichenko, E.V.; Monastyrnaia, M.M.; Kozlovskaia, E.P.; Mol'nar, A.A.; Ivanov, A.C. Interaction investigation of trypsin inhibitor from sea anemone Radianthus macrodactylus with proteases (in Russian). Biomed. Khim. 2006, 52, 595-600.

47. Gladkikh, I.; Monastyrnaya, M.; Leychenko, E.; Zelepuga, E.; Chausova, V.; Isaeva, M.; Anastyuk, S.; Andreev, Y.; Peigneur, S.; Tytgat, J.; Kozlovkaya, E. Atypical reactive center Kunitz-type inhibitor from the sea anemone Heteractis crispa. Mar. Drugs 2012, 10, 1545-1565.

48. Strydom, D.J. Snake venom toxins. Purification and properties of low-molecular-weight polypeptides of Dendroaspis polylepis polylepis (black mamba) venom. Eur. J. Biochem. 1976, 69, 169-176.

49. Guo, C.T.; McClean, S.; Shaw, C.; Rao, P.F.; Ye, M.Y.; Bjourson, A.J. Purification, characterization and molecular cloning of chymotrypsin inhibitor peptides from the venom of Burmese Daboia russelii siamensis. Peptides 2013, 43C, 126-132. 
50. Guo, C.T.; McClean, S.; Shaw, C.; Rao, P.F.; Ye, M.Y.; Bjourson, A.J. Trypsin and chymotrypsin inhibitor peptides from the venom of Chinese Daboia russellii siamensis. Toxicon 2013, 63, 154-164.

51. Hokama, Y.; Iwanaga, S.; Tatsuki, T.; Suzuki, T. Snake venom proteinase inhibitors. III. Isolation of five polypeptide inhibitors from the venoms of Hemachatus haemachatus (Ringhal's corbra) and Naja nivea (Cape cobra) and the complete amino acid sequences of two of them. J. Biochem. 1976, 79, 559-578.

52. Ritonja, A.; Turk, V.; Gubensek, F. Serine proteinase inhibitors from Vipera ammodytes venom. Isolation and kinetic studies. Eur. J. Biochem. 1983, 133, 427-432.

53. Ritonja, A.; Meloun, B.; Gubensek, F. The primary structure of Vipera ammodytes venom trypsin inhibitor I. Biochim. Biophys. Acta 1983, 748, 429-435.

54. Liu, C.S.; Wu, T.C.; Lo, T.B. Complete amino acid sequences of two protease inhibitors in the venom of Bungarus fasciatus. Int. J. Pept. Protein Res. 1983, 21, 209-215.

55. Lu, J.; Yang, H.; Yu, H.; Gao, W.; Lai, R.; Liu, J.; Liang, X. A novel serine protease inhibitor from Bungarus fasciatus venom. Peptides 2008, 29, 369-374.

56. Shafqat, J.; Beg, O.U.; Yin, S.J.; Zaidi, Z.H.; Jornvall, H. Primary structure and functional properties of cobra (Naja naja naja) venom Kunitz-type trypsin inhibitor. Eur. J. Biochem. 1990, 194, 337-341.

57. Zhou, X.D.; Jin, Y.; Lu, Q.M.; Li, D.S.; Zhu, S.W.; Wang, W.Y.; Xiong, Y.L. Purification, characterization and primary structure of a chymotrypsin inhibitor from Naja atra venom. Comp. Biochem. Physiol. B Biochem. Mol. Biol. 2004, 137, 219-224.

58. Cheng, Y.C.; Yan, F.J.; Chang, L.S. Taiwan cobra chymotrypsin inhibitor: Cloning, functional expression and gene organization. Biochim. Biophys. Acta 2005, 1747, 213-220.

59. Chang, L.; Chung, C.; Huang, H.B.; Lin, S. Purification and characterization of a chymotrypsin inhibitor from the venom of Ophiophagus hannah (King Cobra). Biochem. Biophys. Res. Commun. 2001, 283, 862-867.

60. He, Y.Y.; Liu, S.B.; Lee, W.H.; Qian, J.Q.; Zhang, Y. Isolation, expression and characterization of a novel dual serine protease inhibitor, OH-TCI, from king cobra venom. Peptides 2008, 29, 1692-1699.

61. Chang, L.S.; Wang, J.J.; Cheng, Y.C.; Chou, W.M. Genetic organization of Bungarus multicinctus protease inhibitor-like proteins. Toxicon 2008, 51, 1490-1495.

62. Possani, L.D.; Martin, B.M.; Yatani, A.; Mochca-Morales, J.; Zamudio, F.Z.; Gurrola, G.B.; Brown, A.M. Isolation and physiological characterization of taicatoxin, a complex toxin with specific effects on calcium channels. Toxicon 1992, 30, 1343-1364.

63. Earl, S.T.; Richards, R.; Johnson, L.A.; Flight, S.; Anderson, S.; Liao, A.; de Jersey, J.; Masci, P.P.; Lavin, M.F. Identification and characterisation of Kunitz-type plasma kallikrein inhibitors unique to Oxyuranus sp. snake venoms. Biochimie 2012, 94, 365-373.

64. Morjen, M.; Kallech-Ziri, O.; Bazaa, A.; Othman, H.; Mabrouk, K.; Zouari-Kessentini, R.; Sanz, L.; Calvete, J.J.; Srairi-Abid, N.; El Ayeb, M.; et al. PIVL, a new serine protease inhibitor from Macrovipera lebetina transmediterranea venom, impairs motility of human glioblastoma cells. Matrix Biol. 2013, 32, 52-62. 
65. Inagaki, H.; Kimoto, H.; Yamauchi, Y.; Toriba, M.; Kubo, T. Functional characterization of Kunitz-type protease inhibitor Pr-mulgins identified from New Guinean Pseudechis australis. Toxicon 2012, 59, 74-80.

66. Chhatwal, G.S.; Habermann, E. Neurotoxins, protease inhibitors and histamine releasers in the venom of the Indian red scorpion (Buthus tamulus): Isolation and partial characterization. Toxicon 1981, 19, 807-823.

67. Schwartz, E.F.; Diego-Garcia, E.; Rodríguez de la Vega, R.C.; Possani, L.D. Transcriptome analysis of the venom gland of the Mexican scorpion Hadrurus gertschi (Arachnida: Scorpiones). BMC Genomics 2007, 8, 119.

68. Chen, Z.Y.; Hu, Y.T.; Yang, W.S.; He, Y.W.; Feng, J.; Wang, B.; Zhao, R.M.; Ding, J.P.; Cao, Z.J.; Li, W.X.; Wu, Y.L. Hg1, novel peptide inhibitor specific for Kv1.3 channels from first scorpion Kunitz-type potassium channel toxin family. J. Biol. Chem. 2012, 287, 13813-13821.

69. Chen, Z.; Wang, B.; Hu, J.; Yang, W.; Cao, Z.; Zhuo, R.; Li, W.; Wu, Y. SjAPI, the first functionally characterized Ascaris-type protease inhibitor from animal venoms. PLoS One 2013, 8, e57529.

70. Wan, H.; Lee, K.S.; Kim, B.Y.; Zou, F.M.; Yoon, H.J.; Je, Y.H.; Li, J.; Jin, B.R. A spider-derived Kunitz-type serine protease inhibitor that acts as a plasmin inhibitor and an elastase inhibitor. PLoS One 2013, 8, e53343.

71. Wan, H.; Lee, K.S.; Kim, B.Y.; Yuan, M.; Zhan, S.; You, H.; Li, J.; Jin, B.R. A spider (Araneus ventricosus) chymotrypsin inhibitor that acts as an elastase inhibitor and a microbial serine protease inhibitor. Comp. Biochem. Physiol. B Biochem. Mol. Biol. 2013, 165, 36-41.

72. Mignogna, G.; Pascarella, S.; Wechselberger, C.; Hinterleitner, C.; Mollay, C.; Amiconi, G.; Barra, D.; Kreil, G. BSTI, a trypsin inhibitor from skin secretions of Bombina bombina related to protease inhibitors of nematodes. Protein Sci. 1996, 5, 357-362.

73. Lai, R.; Liu, H.; Lee, W.H.; Zhang, Y. Identification and cloning of a trypsin inhibitor from skin secretions of Chinese red-belly toad Bombina maxima. Comp. Biochem. Physiol. B Biochem. Mol. Biol. 2002, 131, 47-53.

74. Ali, M.F.; Lips, K.R.; Knoop, F.C.; Fritzsch, B.; Miller, C.; Conlon, J.M. Antimicrobial peptides and protease inhibitors in the skin secretions of the crawfish frog, Rana areolata. Biochim. Biophys. Acta 2002, 1601, 55-63.

75. Chen, T.; Shaw, C. Identification and molecular cloning of novel trypsin inhibitor analogs from the dermal venom of the Oriental fire-bellied toad (Bombina orientalis) and the European yellow-bellied toad (Bombina variegata). Peptides 2003, 24, 873-880.

76. Lu, X.; Ma, Y.; Wu, J.; Lai, R. Two serine protease inhibitors from the skin secretions of the toad, Bombina microdeladigitora. Comp. Biochem. Physiol. B Biochem. Mol. Biol. 2008, 149, 608-612.

77. Wu, J.; Liu, H.; Yang, H.; Yu, H.; You, D.; Ma, Y.; Ye, H.; Lai, R. Proteomic analysis of skin defensive factors of tree frog Hyla simplex. J. Proteome Res. 2011, 10, 4230-4240.

78. Zhao, Y.; Jin, Y.; Lee, W.H.; Zhang, Y. Isolation and preliminary characterization of a $22-\mathrm{kDa}$ protein with trypsin inhibitory activity from toad Bufo andrewsi skin. Toxicon 2005, 46, 277-281. 
79. Zhao, Y.; Jin, Y.; Wei, S.S.; Lee, W.H.; Zhang, Y. Purification and characterization of an irreversible serine protease inhibitor from skin secretions of Bufo andrewsi. Toxicon 2005, 46, 635-640.

80. Zhang, Y.; Wang, M.; Wei, S. Isolation and characterization of a trypsin inhibitor from the skin secretions of Kaloula pulchra hainana. Toxicon 2010, 56, 502-507.

81. Gebhard, L.G.; Carrizo, F.U.; Stern, A.L.; Burgardt, N.I.; Faivovich, J.; Lavilla, E.; Ermacora, M.R. A Kazal prolyl endopeptidase inhibitor isolated from the skin of Phyllomedusa sauvagii. Eur. J. Biochem. 2004, 271, 2117-2126.

82. Neiva, M.; Vargas, D.C.; Conceição, K.; Rádis-Baptista, G.; Assakura, M.T.; Jared, C.; Hayashi, M.A. Gene expression analysis by ESTs sequencing of the Brazilian frog Phyllomedusa nordestina skin glands. Toxicon 2013, 61, 139-150.

83. Li, R.; Wang, H.; Jiang, Y.; Yu, Y.; Wang, L.; Zhou, M.; Zhang, Y.; Chen, T.; Shaw, C. A novel Kazal-type trypsin inhibitor from the skin secretion of the Central American red-eyed leaf frog, Agalychnis callidryas. Biochimie 2012, 94, 1376-1381.

84. Wang, H.; Wang, L.; Zhou, M.; Yang, M.; Ma, C.; Chen, T.; Zhang, Y.; Zeller, M.; Hornshaw, M.; Shaw, C. Functional peptidomics of amphibian skin secretion: A novel Kunitz-type chymotrypsin inhibitor from the African hyperoliid frog, Kassina senegalensis. Biochimie 2012, 94, 891-899.

85. You, D.; Hong, J.; Rong, M.; Yu, H.; Liang, S.; Ma, Y.; Yang, H.; Wu, J.; Lin, D.; Lai, R. The first gene-encoded amphibian neurotoxin. J. Biol. Chem. 2009, 284, 22079-22086.

86. Li, J.; Wu, J.; Wang, Y.; Xu, X.; Liu, T.; Lai, R.; Zhu, H. A small trypsin inhibitor from the frog of Odorrana grahami. Biochimie 2008, 90, 1356-1361.

87. Song, G.; Zhou, M.; Chen, W.; Chen, T.; Walker, B.; Shaw, C. HV-BBI-A novel amphibian skin Bowman-Birk-like trypsin inhibitor. Biochem. Biophys. Res. Commun. 2008, 372, 191-196.

88. Yang, X.; Wang, Y.; Lu, Z.; Zhai, L.; Jiang, J.; Liu, J.; Yu, H. A novel serine protease inhibitor from the venom of Vespa bicolor Fabricius. Comp. Biochem. Physiol. B Biochem. Mol. Biol. 2009, 153, 116-120.

89. Qiu, Y.; Lee, K.S.; Choo, Y.M.; Kong, D.; Yoon, H.J.; Jin, B.R. Molecular cloning and antifibrinolytic activity of a serine protease inhibitor from bumblebee (Bombus terrestris) venom. Toxicon 2013, 63, 1-6.

90. Lenarcic, B.; Turk, V. Thyroglobulin type-1 domains in equistatin inhibit both papain-like cysteine proteinases and cathepsin D. J. Biol. Chem. 1999, 274, 563-566.

91. Strukelj, B.; Lenarcic, B.; Gruden, K.; Pungercar, J.; Rogelj, B.; Turk, V.; Bosch, D.; Jongsma, M.A. Equistatin, a protease inhibitor from the sea anemone Actinia equina is composed of three structural and functional domains. Biochem. Biophys. Res. Commun. 2000, 269, 732-736.

92. Honma, T.; Shiomi, K. Peptide toxins in sea anemones: Structural and functional aspects. Mar. Biotechnol. (NY) 2006, 8, 1-10.

93. Frazão, B.; Vasconcelos, V.; Antunes, A. Sea anemone (Cnidaria, Anthozoa, Actiniaria) toxins: An overview. Mar. Drugs 2012, 10, 1812-1851.

94. Bayrhuber, M.; Graf, R.; Ferber, M.; Zweckstetter, M.; Imperial, J.; Garrett, J.E.; Olivera, B.M.; Terlau, H.; Becker, S. Production of recombinant Conkunitzin-S1 in Escherichia coli. Protein Expr. Purif. 2006, 47, 640-644. 
95. Harvey, A.L. Twenty years of dendrotoxins. Toxicon 2001, 39, 15-26.

96. Owen, D.G.; Hall, A.; Stephens, G.; Stow, J.; Robertson, B. The relative potencies of dendrotoxins as blockers of the cloned voltage-gated $\mathrm{K}^{+}$channel, $\mathrm{mK}_{\mathrm{v}} 1.1(\mathrm{MK}-1)$, when stably expressed in Chinese hamster ovary cells. Br. J. Pharmacol. 1997, 120, 1029-1034.

97. Hopkins, W.F. Toxin and subunit specificity of blocking affinity of three peptide toxins for heteromultimeric, voltage-gated potassium channels expressed in Xenopus oocytes. J. Pharmacol. Exp. Ther. 1998, 285, 1051-1060.

98. Tytgat, J.; Vandenberghe, I.; Ulens, C.; van Beeumen, J. New polypeptide components purified from mamba venom. FEBS Lett. 2001, 491, 217-221.

99. Chen, Z.; Luo, F.; Feng, J.; Yang, W.; Zeng, D.; Zhao, R.; Cao, Z.; Liu, M.; Li, W.; Jiang, L.; $\mathrm{Wu}, \mathrm{Y}$. Genomic and structural characterization of Kunitz-type peptide LmKTT-1a highlights diversity and evolution of scorpion potassium channel toxins. PLoS One 2013, 8, e60201.

100. Monastyrnaya, M.M.; Zykova, T.A.; Apalikova, O.V.; Shwets, T.V.; Kozlovskaya, E.P. Biologically active polypeptides from the tropical sea anemone Radianthus macrodactylus. Toxicon 2002, 40, 1197-1217.

101. Takahashi, H.; Iwanaga, S.; Suzuki, T. Isolation of a novel inhibitor of kallikrein, plasmin and trypsin from the venom of Russell's viper (Vipera russelli). FEBS Lett. 1972, 27, 207-210.

102. Anderluh, G.; Podlesek, Z.; Macek, P. A common motif in proparts of Cnidarian toxins and nematocyst collagens and its putative role. Biochim. Biophys. Acta 2000, 1476, 372-376.

103. Craig, A.G.; Bandyopadhyay, P.; Olivera, B.M. Post-translationally modified neuropeptides from Conus venoms. Eur. J. Biochem. 1999, 264, 271-275.

104. Lewis, R.J.; Dutertre, S.; Vetter, I.; Christie, M.J. Conus venom peptide pharmacology. Pharmacol. Rev. 2012, 64, 259-298.

105. Bayrhuber, M.; Vijayan, V.; Ferber, M.; Graf, R.; Korukottu, J.; Imperial, J.; Garrett, J.E.; Olivera, B.M.; Terlau, H.; Zweckstetter, M.; Becker, S. Conkunitzin-S1 is the first member of a new Kunitz-type neurotoxin family. Structural and functional characterization. J. Biol. Chem. 2005, 280, 23766-23770.

106. Elliger, C.A.; Richmond, T.A.; Lebaric, Z.N.; Pierce, N.T.; Sweedler, J.V.; Gilly, W.F. Diversity of conotoxin types from Conus californicus reflects a diversity of prey types and a novel evolutionary history. Toxicon 2011, 57, 311-322.

107. Hu, H.; Bandyopadhyay, P.K.; Olivera, B.M.; Yandell, M. Characterization of the Conus bullatus genome and its venom-duct transcriptome. BMC Genomics 2011, 12, 60.

108. Strydom, D.J. Protease inhibitors as snake venom toxins. Nat. New Biol. 1973, 243, 88-89.

109. Harvey, A.L.; Karlsson, E. Dendrotoxin from the venom of the green mamba, Dendroaspis angusticeps. Naunyn Schmiedebergs Arch. Pharmacol. 1980, 312, 1-6.

110. Harvey, A.L.; Robertson, B. Dendrotoxins: Structure-activity relationships and effects on potassium ion channels. Curr. Med. Chem. 2004, 11, 3065-3072.

111. Schweitz, H.; Heurteaux, C.; Bois, P.; Moinier, D.; Romey, G.; Lazdunski, M. Calcicludine, a venom peptide of the Kunitz-type protease inhibitor family, is a potent blocker of high-threshold $\mathrm{Ca}^{2+}$ channels with a high affinity for L-type channels in cerebellar granule neurons. Proc. Natl. Acad. Sci. USA 1994, 91, 878-882. 
112. Gilquin, B.; Lecoq, A.; Desne, F.; Guenneugues, M.; Zinn-Justin, S.; Menez, A. Conformational and functional variability supported by the BPTI fold: Solution structure of the $\mathrm{Ca}^{2+}$ channel blocker calcicludine. Proteins 1999, 34, 520-532.

113. Kondo, K.; Toda, H.; Narita, K.; Lee, C.Y. Amino acid sequence of $\beta_{2}$-bungarotoxin from Bungarus multicinctus venom. The amino acid substitutions in the B chains. J. Biochem. 1982, 91, 1519-1530.

114. Wu, P.F.; Wu, S.N.; Chang, C.C.; Chang, L.S. Cloning and functional expression of B chains of $\beta$-bungarotoxins from Bungarus multicinctus (Taiwan banded krait). Biochem. J. 1998, 334, 87-92.

115. Takahashi, H.; Iwanaga, S.; Kitagawa, T.; Hokama, Y.; Suzuki, T. Snake venom proteinase inhibitors. II. Chemical structure of inhibitor II isolated from the venom of Russell's viper (Vipera russelli). J. Biochem. 1974, 76, 721-733.

116. Zupunski, V.; Kordis, D.; Gubensek, F. Adaptive evolution in the snake venom Kunitz/BPTI protein family. FEBS Lett. 2003, 547, 131-136.

117. Siddiqi, A.R.; Zaidi, Z.H.; Jornvall, H. Purification and characterization of a Kunitz-type trypsin inhibitor from Leaf-nosed viper venom. FEBS Lett. 1991, 294, 141-143.

118. Chen, C.; Hsu, C.H.; Su, N.Y.; Lin, Y.C.; Chiou, S.H.; Wu, S.H. Solution structure of a Kunitz-type chymotrypsin inhibitor isolated from the elapid snake Bungarus fasciatus. J. Biol. Chem. 2001, 276, 45079-45087.

119. Shafqat, J.; Zaidi, Z.H.; Jornvall, H. Purification and characterization of a chymotrypsin Kunitz inhibitor type of polypeptide from the venom of cobra (Naja naja naja). FEBS Lett. 1990, 275, 6-8.

120. Doorty, K.B.; Bevan, S.; Wadsworth, J.D.; Strong, P.N. A novel small conductance $\mathrm{Ca}^{2+}$-activated $\mathrm{K}^{+}$channel blocker from Oxyuranus scutellatus taipan venom. Re-evaluation of taicatoxin as a selective $\mathrm{Ca}^{2+}$ channel probe. J. Biol. Chem. 1997, 272, 19925-19930.

121. Filippovich, I.; Sorokina, N.; Masci, P.P.; de Jersey, J.; Whitaker, A.N.; Winzor, D.J.; Gaffney, P.J.; Lavin, M.F. A family of textilinin genes, two of which encode proteins with antihaemorrhagic properties. Br. J. Haematol. 2002, 119, 376-384.

122. Flight, S.; Johnson, L.; Trabi, M.; Gaffney, P.; Lavin, M.; de Jersey, J.; Masci, P. Comparison of textilinin-1 with aprotinin as serine protease inhibitors and as antifibrinolytic agents. Pathophysiol. Haemost. Thromb. 2005, 34, 188-193.

123. Flight, S.M.; Johnson, L.A.; Du, Q.S.; Warner, R.L.; Trabi, M.; Gaffney, P.J.; Lavin, M.F.; de Jersey, J.; Masci, P.P. Textilinin-1, an alternative anti-bleeding agent to aprotinin: Importance of plasmin inhibition in controlling blood loss. Br. J. Haematol. 2009, 145, 207-211.

124. Mangano, D.T.; Tudor, I.C.; Dietzel, C. The risk associated with aprotinin in cardiac surgery. N. Engl. J. Med. 2006, 354, 353-365.

125. St Pierre, L.; Earl, S.T.; Filippovich, I.; Sorokina, N.; Masci, P.P.; De Jersey, J.; Lavin, M.F. Common evolution of waprin and kunitz-like toxin families in Australian venomous snakes. Cell Mol. Life Sci. 2008, 65, 4039-4054. 
126. Chatrath, S.T.; Chapeaurouge, A.; Lin, Q.; Lim, T.K.; Dunstan, N.; Mirtschin, P.; Kumar, P.P.; Kini, R.M. Identification of novel proteins from the venom of a cryptic snake Drysdalia coronoides by a combined transcriptomics and proteomics approach. J. Proteome Res. 2011, 10, 739-750.

127. Jiang, Y.; Li, Y.; Lee, W.; Xu, X.; Zhang, Y.; Zhao, R.; Wang, W. Venom gland transcriptomes of two elapid snakes (Bungarus multicinctus and Naja atra) and evolution of toxin genes. BMC Genomics 2011, 12, 1.

128. Ramazanova, A.S.; Fil'kin, S.; Starkov, V.G.; Utkin Iu, N. Molecular cloning and analysis of cDNA sequences encoding serine proteinase and Kunitz type inhibitor in venom gland of Vipera nikolskii viper (in Russian). Bioorg. Khim. 2011, 37, 374-385.

129. Corrêa-Netto, C.; Junqueira-de-Azevedo Ide, L.; Silva, D.A.; Ho, P.L.; Leitão-de-Araújo, M.; Alves, M.L.; Sanz, L.; Foguel, D.; Zingali, R.B.; Calvete, J.J. Snake venomics and venom gland transcriptomic analysis of Brazilian coral snakes, Micrurus altirostris and M. corallinus. J. Proteomics 2011, 74, 1795-1809.

130. Turk, V.; Bode, W. The cystatins: protein inhibitors of cysteine proteinases. FEBS Lett. 1991, 285, 213-219.

131. Richards, R.; St Pierre, L.; Trabi, M.; Johnson, L.A.; de Jersey, J.; Masci, P.P.; Lavin, M.F. Cloning and characterisation of novel cystatins from elapid snake venom glands. Biochimie 2011, 93, 659-668.

132. Evans, H.J.; Barrett, A.J. A cystatin-like cysteine proteinase inhibitor from venom of the African puff adder (Bitis arietans). Biochem. J. 1987, 246, 795-797.

133. Brillard-Bourdet, M.; Nguyen, V.; Ferrer-di Martino, M.; Gauthier, F.; Moreau, T. Purification and characterization of a new cystatin inhibitor from Taiwan cobra (Naja naja atra) venom. Biochem. J. 1998, 331, 239-244.

134. Mashiko, H.; Takahashi, H. Cysteine proteinase inhibitors in elapid and hydrophiid snake venoms. Toxicon 2002, 40, 1275-1281.

135. Ferreira, S.H. A bradykinin-potentiating factor (BFP) present in the venom of Bothrops jararca. Br. J. Pharmacol. Chemother. 1965, 24, 163-169.

136. Ferreira, S.H.; Bartelt, D.C.; Greene, L.J. Isolation of bradykinin-potentiating peptides from Bothrops jararaca venom. Biochemistry 1970, 9, 2583-2593.

137. Stewart, J.M.; Ferreira, S.H.; Greene, L.J. Bradykinin potentiating peptide PCA-Lys-Trp-Ala-Pro: An inhibitor of the pulmonary inactivation of Bradykinin and conversion of angiotensin I to II. Biochem. Pharmacol. 1971, 20, 1557-1567.

138. Opie, L.H.; Kowolik, H. The discovery of captopril: From large animals to small molecules. Cardiovasc. Res. 1995, 30, 18-25.

139. Higuchi, S.; Murayama, N.; Saguchi, K.; Ohi, H.; Fujita, Y.; da Silva, N.J., Jr.; de Siqueira, R.J.; Lahlou, S.; Aird, S.D. A novel peptide from the ACEI/BPP-CNP precursor in the venom of Crotalus durissus collilineatus. Comp. Biochem. Physiol. C Toxicol. Pharmacol. 2006, 144, 107-121.

140. Cidade, D.A.; Simão, T.A.; Davila, A.M.; Wagner, G.; Junqueira-de-Azevedo, I.L.; Ho, P.L.; Bon, C.; Zingali, R.B.; Albano, R.M. Bothrops jararaca venom gland transcriptome: Analysis of the gene expression pattern. Toxicon 2006, 48, 437-461. 
141. Munawar, A.; Trusch, M.; Georgieva, D.; Spencer, P.; Frochaux, V.; Harder, S.; Arni, R.K.; Duhalov, D.; Genov, N.; Schluter, H.; Betzel, C. Venom peptide analysis of Vipera ammodytes meridionalis (Viperinae) and Bothrops jararacussu (Crotalinae) demonstrates subfamily-specificity of the peptidome in the family Viperidae. Mol. Biosyst. 2011, 7, 3298-3307.

142. Chi, C.W.; Wang, S.Z.; Xu, L.G.; Wang, M.Y.; Lo, S.S.; Huang, W.D. Structure-function studies on the bradykinin potentiating peptide from Chinese snake venom (Agkistrodon halys Pallas). Peptides 1985, 6, 339-342.

143. Higuchi, S.; Murayama, N.; Saguchi, K.; Ohi, H.; Fujita, Y.; Camargo, A.C.; Ogawa, T.; Deshimaru, M.; Ohno, M. Bradykinin-potentiating peptides and $C$-type natriuretic peptides from snake venom. Immunopharmacology 1999, 44, 129-135.

144. Grasberger, B.L.; Clore, G.M.; Gronenborn, A.M. High-resolution structure of Ascaris trypsin inhibitor in solution: Direct evidence for a $\mathrm{pH}$-induced conformational transition in the reactive site. Structure 1994, 2, 669-678.

145. Brazón, J.; D'Suze, G.; D'Errico, M.L.; Arocha-Piñango, C.L.; Guerrero, B. Discreplasminin, a plasmin inhibitor isolated from Tityus discrepans scorpion venom. Arch. Toxicol. 2009, 83, 669-678.

146. Silva, E.C.; Camargos, T.S.; Maranhao, A.Q.; Silva-Pereira, I.; Silva, L.P.; Possani, L.D.; Schwartz, E.F. Cloning and characterization of cDNA sequences encoding for new venom peptides of the Brazilian scorpion Opisthacanthus cayaporum. Toxicon 2009, 54, 252-261.

147. Gremski, L.H.; da Silveira, R.B.; Chaim, O.M.; Probst, C.M.; Ferrer, V.P.; Nowatzki, J.; Weinschutz, H.C.; Madeira, H.M.; Gremski, W.; Nader, H.B.; et al. A novel expression profile of the Loxosceles intermedia spider venomous gland revealed by transcriptome analysis. Mol. Biosyst. 2010, 6, 2403-2416.

148. Zhang, Y.X.; Lai, R.; Lee, W.H.; Zhang, Y. Frog albumin is expressed in skin and characterized as a novel potent trypsin inhibitor. Protein Sci. 2005, 14, 2469-2477.

149. Hisada, M.; Satake, H.; Masuda, K.; Aoyama, M.; Murata, K.; Shinada, T.; Iwashita, T.; Ohfune, Y.; Nakajima, T. Molecular components and toxicity of the venom of the solitary wasp, Anoplius samariensis. Biochem. Biophys. Res. Commun. 2005, 330, 1048-1054.

150. Parkinson, N.M.; Conyers, C.; Keen, J.; MacNicoll, A.; Smith, I.; Audsley, N.; Weaver, R. Towards a comprehensive view of the primary structure of venom proteins from the parasitoid wasp Pimpla hypochondriaca. Insect Biochem. Mol. Biol. 2004, 34, 565-571.

151. Choo, Y.M.; Lee, K.S.; Yoon, H.J.; Kim, B.Y.; Sohn, M.R.; Roh, J.Y.; Je, Y.H.; Kim, N.J.; Kim, I.; Woo, S.D.; et al. Dual function of a bee venom serine protease: Prophenoloxidase-activating factor in arthropods and fibrin(ogen)olytic enzyme in mammals. PLoS One 2010, 5, e10393.

152. Kim, B.Y.; Lee, K.S.; Wan, H.; Zou, F.M.; Choi, Y.S.; Yoon, H.J.; Kwon, H.W.; Je, Y.H.; Jin, B.R. Anti-elastolytic activity of a honeybee (Apis cerana) chymotrypsin inhibitor. Biochem. Biophys. Res. Commun. 2013, 430, 144-149.

153. Skarzynski, T. Crystal structure of $\alpha$-dendrotoxin from the green mamba venom and its comparison with the structure of bovine pancreatic trypsin inhibitor. J. Mol. Biol. 1992, 224, $671-683$. 
154. Grissmer, S.; Nguyen, A.N.; Aiyar, J.; Hanson, D.C.; Mather, R.J.; Gutman, G.A.; Karmilowicz, M.J.; Auperin, D.D.; Chandy, K.G. Pharmacological characterization of five cloned voltage-gated $\mathrm{K}^{+}$channels, types $\mathrm{Kv} 1.1,1.2,1.3$, 1.5, and 3.1, stably expressed in mammalian cell lines. Mol. Pharmacol. 1994, 45, 1227-1234.

155. Robertson, B.; Owen, D.; Stow, J.; Butler, C.; Newland, C. Novel effects of dendrotoxin homologues on subtypes of mammalian $\mathrm{K}_{\mathrm{v}} 1$ potassium channels expressed in Xenopus oocytes. FEBS Lett. 1996, 383, 26-30.

156. Joubert, F.J.; Strydom, D.J. Snake venoms. The amino-acid sequence of trypsin inhibitor E of Dendroaspis polylepis polylepis (Black Mamba) venom. Eur. J. Biochem. 1978, 87, 191-198.

157. Harvey, A.L. Recent studies on dendrotoxins and potassium ion channels. Gen. Pharmacol. 1997, 28, 7-12.

158. Harvey, A.L.; Rowan, E.G.; Vatanpour, H.; Engstrom, A.; Westerlund, B.; Karlsson, E. Changes to biological activity following acetylation of dendrotoxin I from Dendroaspis polylepis (black mamba). Toxicon 1997, 35, 1263-1273.

159. Gasparini, S.; Danse, J.M.; Lecoq, A.; Pinkasfeld, S.; Zinn-Justin, S.; Young, L.C.; de Medeiros, C.C.; Rowan, E.G.; Harvey, A.L.; Menez, A. Delineation of the functional site of $\alpha$-dendrotoxin. The functional topographies of dendrotoxins are different but share a conserved core with those of other Kv1 potassium channel-blocking toxins. J. Biol. Chem. 1998, 273, 25393-25403.

160. Smith, L.A.; Reid, P.F.; Wang, F.C.; Parcej, D.N.; Schmidt, J.J.; Olson, M.A.; Dolly, J.O. Site-directed mutagenesis of dendrotoxin $\mathrm{K}$ reveals amino acids critical for its interaction with neuronal $\mathrm{K}^{+}$channels. Biochemistry 1997, 36, 7690-7696.

161. Wang, F.C.; Bell, N.; Reid, P.; Smith, L.A.; McIntosh, P.; Robertson, B.; Dolly, J.O. Identification of residues in dendrotoxin $\mathrm{K}$ responsible for its discrimination between neuronal $\mathrm{K}^{+}$channels containing $\mathrm{K}_{\mathrm{v}} 1.1$ and $1.2 \alpha$ subunits. Eur. J. Biochem. 1999, 263, 222-229.

162. Danse, J.M.; Rowan, E.G.; Gasparini, S.; Ducancel, F.; Vatanpour, H.; Young, L.C.; Poorheidari, G.; Lajeunesse, E.; Drevet, P.; Menez, R.; et al. On the site by which $\alpha$-dendrotoxin binds to voltage-dependent potassium channels: Site-directed mutagenesis reveals that the lysine triplet 28-30 is not essential for binding. FEBS Lett. 1994, 356, 153-158.

163. Imredy, J.P.; MacKinnon, R. Energetic and structural interactions between $\delta$-dendrotoxin and a voltage-gated potassium channel. J. Mol. Biol. 2000, 296, 1283-1294.

164. Lee, C.Y.; Chang, S.L.; Kau, S.T.; Luh, S.H. Chromatographic separation of the venom of Bungarus multicinctus and characterization of its components. J. Chromatogr. 1972, 72, 71-82.

165. MacDermot, J.; Westgaard, R.H.; Thompson, E.J. $\beta$-Bungarotoxin. Separation of two discrete proteins with different synaptic actions. Biochem. J. 1978, 175, 271-279.

166. Ueno, E.; Rosenberg, P. Mechanism of action of $\beta$-bungarotoxin, a presynaptically acting phospholipase $\mathrm{A}_{2}$ neurotoxin: Its effect on protein phosphorylation in rat brain synaptosomes. Toxicon 1996, 34, 1219-1227.

167. Shi, Y.; Gu, C.; Xu, Y. Four types of potassium currents in motor nerve terminals of snake. Sci. China C Life Sci. 1997, 40, 593-603. 
168. Schmidt, R.R.; Betz, H.; Rehm, H. Inhibition of $\beta$-bungarotoxin binding to brain membranes by mast cell degranulating peptide, toxin I, and ethylene glycol bis ( $\beta$-aminoethyl ether)- $N, N, N^{\prime}$, $N^{\prime}$-tetraacetic acid. Biochemistry 1988, 27, 963-967.

169. Chu, S.T.; Chu, C.C.; Tseng, C.C.; Chen, Y.H. Met-8 of the $\beta_{1}$-bungarotoxin phospholipase $A_{2}$ subunit is essential for the phospholipase $\mathrm{A}_{2}$-independent neurotoxic effect. Biochem. J. 1993, 295, 713-718.

170. Larkin, M.A.; Blackshields, G.; Brown, N.P.; Chenna, R.; McGettigan, P.A.; McWilliam, H.; Valentin, F.; Wallace, I.M.; Wilm, A.; Lopez, R.; et al. Clustal W and Clustal X version 2.0. Bioinformatics 2007, 23, 2947-2948.

171. Goodstadt, L.; Ponting, C.P. CHROMA: Consensus-based colouring of multiple alignments for publication. Bioinformatics 2001, 17, 845-846.

172. Rodríguez de la Vega, R.C.; Merino, E.; Becerril, B.; Possani, L.D. Novel interactions between $\mathrm{K}^{+}$channels and scorpion toxins. Trends Pharmacol. Sci. 2003, 24, 222-227.

173. Mouhat, S.; de Waard, M.; Sabatier, J.M. Contribution of the functional dyad of animal toxins acting on voltage-gated $\mathrm{K}_{\mathrm{v}} 1$-type channels. J. Pept. Sci. 2005, 11, 65-68.

174. Jin, L.; Wu, Y. Molecular mechanism of $\delta$-dendrotoxin-potassium channel recognition explored by docking and molecular dynamic simulations. J. Mol. Recognit. 2011, 24, 101-107.

175. Otlewski, J.; Jaskolski, M.; Buczek, O.; Cierpicki, T.; Czapinska, H.; Krowarsch, D.; Smalas, A.O.; Stachowiak, D.; Szpineta, A.; Dadlez, M. Structure-function relationship of serine protease-protein inhibitor interaction. Acta Biochim. Pol. 2001, 48, 419-428.

176. Kawamura, K.; Yamada, T.; Kurihara, K.; Tamada, T.; Kuroki, R.; Tanaka, I.; Takahashi, H.; Niimura, N. X-ray and neutron protein crystallographic analysis of the trypsin-BPTI complex. Acta Crystallogr. D Biol. Crystallogr. 2011, 67, 140-148.

177. Laskowski, M., Jr.; Kato, I. Protein inhibitors of proteinases. Annu. Rev. Biochem. 1980, 49, 593-626.

178. Scheidig, A.J.; Hynes, T.R.; Pelletier, L.A.; Wells, J.A.; Kossiakoff, A.A. Crystal structures of bovine chymotrypsin and trypsin complexed to the inhibitor domain of Alzheimer's amyloid $\beta$-protein precursor (APPI) and basic pancreatic trypsin inhibitor (BPTI): Engineering of inhibitors with altered specificities. Protein Sci. 1997, 6, 1806-1824.

179. Navaneetham, D.; Sinha, D.; Walsh, P.N. Mechanisms and specificity of factor XIa and trypsin inhibition by protease nexin 2 and basic pancreatic trypsin inhibitor. J. Biochem. 2010, 148, $467-479$.

180. Fiedler, F. Effects of secondary interactions on the kinetics of peptide and peptide ester hydrolysis by tissue kallikrein and trypsin. Eur. J. Biochem. 1987, 163, 303-312.

181. Grzesiak, A.; Krokoszynska, I.; Krowarsch, D.; Buczek, O.; Dadlez, M.; Otlewski, J. Inhibition of six serine proteinases of the human coagulation system by mutants of bovine pancreatic trypsin inhibitor. J. Biol. Chem. 2000, 275, 33346-33352.

182. Van Nostrand, W.E.; Schmaier, A.H.; Siegel, R.S.; Wagner, S.L.; Raschke, W.C. Enhanced plasmin inhibition by a reactive center lysine mutant of the Kunitz-type protease inhibitor domain of the amyloid $\beta$-protein precursor. J. Biol. Chem. 1995, 270, 22827-22830.

183. Hanson, W.M.; Domek, G.J.; Horvath, M.P.; Goldenberg, D.P. Rigidification of a flexible protease inhibitor variant upon binding to trypsin. J. Mol. Biol. 2007, 366, 230-243. 
184. Fritz, H.; Wunderer, G. Biochemistry and applications of aprotinin, the kallikrein inhibitor from bovine organs. Arzneimittelforschung 1983, 33, 479-494.

185. Humphrey, W.; Dalke, A.; Schulten, K. VMD: Visual molecular dynamics. J. Mol. Graph. 1996, $14,33-38$.

186. Vakorina, T.I.; Gladkikh, I.N.; Monastyrnaia, M.M.; Kozlovskaia, E.P. Conformational stability of serine proteinase inhibitor from the sea anemone Heteractis crispa (in Russian). Bioorg. Khim. 2011, 37, 310-318.

187. Dy, C.Y.; Buczek, P.; Imperial, J.S.; Bulaj, G.; Horvath, M.P. Structure of conkunitzin-S1, a neurotoxin and Kunitz-fold disulfide variant from cone snail. Acta Crystallogr. D Biol. Crystallogr. 2006, 62, 980-990.

188. Dauplais, M.; Lecoq, A.; Song, J.; Cotton, J.; Jamin, N.; Gilquin, B.; Roumestand, C.; Vita, C.; de Medeiros, C.L.; Rowan, E.G.; et al. On the convergent evolution of animal toxins. Conservation of a diad of functional residues in potassium channel-blocking toxins with unrelated structures. J. Biol. Chem. 1997, 272, 4302-4309.

189. Rodríguez de la Vega, R.C.; Possani, L.D. Current views on scorpion toxins specific for $\mathrm{K}^{+}$-channels. Toxicon 2004, 43, 865-875.

190. Berndt, K.D.; Guntert, P.; Wuthrich, K. Nuclear magnetic resonance solution structure of dendrotoxin $\mathrm{K}$ from the venom of Dendroaspis polylepis polylepis. J. Mol. Biol. 1993, 234, $735-750$.

191. Landis, R.C.; Asimakopoulos, G.; Poullis, M.; Haskard, D.O.; Taylor, K.M. The antithrombotic and antiinflammatory mechanisms of action of aprotinin. Ann. Thorac. Surg. 2001, 72, 2169-2175.

192. Ascenzi, P.; Bocedi, A.; Bolognesi, M.; Spallarossa, A.; Coletta, M.; de Cristofaro, R.; Menegatti, E. The bovine basic pancreatic trypsin inhibitor (Kunitz inhibitor): A milestone protein. Curr. Protein Pept. Sci. 2003, 4, 231-251.

193. Bidstrup, B.P.; Royston, D.; Sapsford, R.N.; Taylor, K.M. Reduction in blood loss and blood use after cardiopulmonary bypass with high dose aprotinin (Trasylol). J. Thorac. Cardiovasc. Surg. 1989, 97, 364-372.

194. Lemmer, J.H., Jr.; Stanford, W.; Bonney, S.L.; Breen, J.F.; Chomka, E.V.; Eldredge, W.J.; Holt, W.W.; Karp, R.B.; Laub, G.W.; Lipton, M.J.; et al. Aprotinin for coronary bypass operations: efficacy, safety, and influence on early saphenous vein graft patency. A multicenter, randomized, double-blind, placebo-controlled study. J. Thorac. Cardiovasc. Surg. 1994, 107, 543-551; discussion 551-553.

195. Millers, E.K.; Trabi, M.; Masci, P.P.; Lavin, M.F.; de Jersey, J.; Guddat, L.W. Crystal structure of textilinin-1, a Kunitz-type serine protease inhibitor from the venom of the Australian common brown snake (Pseudonaja textilis). FEBS J. 2009, 276, 3163-3175.

196. Puente, X.S.; Sanchez, L.M.; Overall, C.M.; Lopez-Otin, C. Human and mouse proteases: A comparative genomic approach. Nat. Rev. Genet. 2003, 4, 544-558.

197. Pandey, K.C. Centenary celebrations article: Cysteine proteases of human malaria parasites. J. Parasit. Dis. 2011, 35, 94-103. 
198. Ghany, M.G.; Nelson, D.R.; Strader, D.B.; Thomas, D.L.; Seeff, L.B. An update on treatment of genotype 1 chronic hepatitis $\mathrm{C}$ virus infection: 2011 practice guideline by the American Association for the Study of Liver Diseases. Hepatology 2011, 54, 1433-1444.

199. Randolph, J.T.; Huang, P.P.; Flosi, W.J.; DeGoey, D.; Klein, L.L.; Yeung, C.M.; Flentge, C.; Sun, M.; Zhao, C.; Dekhtyar, T.; et al. Synthesis, antiviral activity, and pharmacokinetic evaluation of P3 pyridylmethyl analogs of oximinoarylsulfonyl HIV-1 protease inhibitors. Bioorg. Med. Chem. 2006, 14, 4035-4046.

200. Lu, D.; Sham, Y.Y.; Vince, R. Design, asymmetric synthesis, and evaluation of pseudosymmetric sulfoximine inhibitors against HIV-1 protease. Bioorg. Med. Chem. 2010, 18, 2037-2048.

201. Wensing, A.M.; van Maarseveen, N.M.; Nijhuis, M. Fifteen years of HIV Protease Inhibitors: Raising the barrier to resistance. Antiviral Res. 2010, 85, 59-74.

(C) 2013 by the authors; licensee MDPI, Basel, Switzerland. This article is an open access article distributed under the terms and conditions of the Creative Commons Attribution license (http://creativecommons.org/licenses/by/3.0/). 